OPEN ACCESS

Edited by:

D. Scott Merrell,

Uniformed Services University, USA

Reviewed by: Martin Wiedmann, Cornell University, USA

Steven R. Blanke,

University of Illinois at

Urbana-Champaign, USA

Chih-Ho Lai,

Chang Gung University, Taiwan

*Correspondence:

Bruce J. Shenker

shenker@upenn.edu

Received: 04 August 2016 Accepted: 15 November 2016 Published: 05 December 2016

Citation:

Scuron MD, Boesze-Battaglia K, Dlakić M and Shenker BJ (2016) The

Cytolethal Distending Toxin

Contributes to Microbial Virulence and Disease Pathogenesis by Acting As a

Tri-Perditious Toxin.

Front. Cell. Infect. Microbiol. 6:168

doi: 10.3389/fcimb.2016.00168

\section{The Cytolethal Distending Toxin Contributes to Microbial Virulence and Disease Pathogenesis by Acting As a Tri-Perditious Toxin}

\author{
Monika D. Scuron ${ }^{1}$, Kathleen Boesze-Battaglia ${ }^{2}$, Mensur Dlakić ${ }^{3}$ and Bruce J. Shenker ${ }^{1 \star}$ \\ ${ }^{1}$ Department of Pathology, School of Dental Medicine, University of Pennsylvania, Philadelphia, PA, USA, ${ }^{2}$ Department of \\ Biochemistry, School of Dental Medicine, University of Pennsylvania, Philadelphia, PA, USA, ${ }^{3}$ Department of Microbiology \\ and Immunology, Montana State University, Bozeman, MT, USA
}

This review summarizes the current status and recent advances in our understanding of the role that the cytolethal distending toxin (Cdt) plays as a virulence factor in promoting disease by toxin-producing pathogens. A major focus of this review is on the relationship between structure and function of the individual subunits that comprise the $A B_{2} C d t$ holotoxin. In particular, we concentrate on the molecular mechanisms that characterize this toxin and which account for the ability of Cdt to intoxicate multiple cell types by utilizing a ubiquitous binding partner on the cell membrane. Furthermore, we propose a paradigm shift for the molecular mode of action by which the active Cdt subunit, CdtB, is able to block a key signaling cascade and thereby lead to outcomes based upon programming and the role of the phosphatidylinositol 3-kinase (PI-3K) in a variety of cells. Based upon the collective Cdt literature, we now propose that Cdt is a unique and potent virulence factor capable of acting as a tri-perditious toxin that impairs host defenses by: (1) disrupting epithelial barriers; (2) suppressing acquired immunity; (3) promoting pro-inflammatory responses. Thus, Cdt plays a key role in facilitating the early stages of infection and the later stages of disease progression by contributing to persistence and impairing host elimination.

Keywords: toxin, virulence, PI-3 kinase, inflammation, epithelial cells, lymphocytes, macrophages

\section{INTRODUCTION}

The cytolethal distending toxin (Cdt) was first described by Johnson and Lior (1988a,b) as a heat-labile toxin present in culture filtrates obtained from clinical isolates of Campylobacter spp. (including C. jejuni, C. coli, C. fetus, C. lari), Escherichia coli and Shigella dysenteriae. Specifically, Cdt-containing filtrates were reported to adversely affect $\mathrm{CHO}$ cells, Vero cells, HeLa cells, and Hep- 2 cells by inducing a progressive distention over $96 \mathrm{~h}$ and eventually leading to loss of cell vitality between 96 and $120 \mathrm{~h}$. Interestingly, the murine adrenal tumor cell line, Y-1, was not susceptible to Cdt toxicity. This was a key observation as Y-1 cells were commonly used to assess the classic heat-labile toxin (LT), thereby allowing these investigators to proclaim the discovery of a new and unique toxin. To date there has been much progress on our understanding of Cdts since the report of these seminal observations. For instance, Cdts are now known to represent a conserved 
and highly distributed family of putative virulence factors produced by a diverse group of more than $30 \gamma$ - and $\varepsilon$ Proteobacteria which are responsible for chronic infection and inflammatory disease typically affecting mucocutaneous tissue (summarized in Table 1). Human pathogens that produce Cdt include: an oral pathogen, a genital pathogen responsible for sexually transmitted chancroid, gastric pathogens, and carcinogenic pathogens; these include both human and animal pathogens (Whitehouse et al., 1998; Shenker et al., 1999; LaraTejero and Galán, 2001; Haghjoo and Galán, 2004; Thelastam and Frisan, 2004; Young et al., 2004; Ge et al., 2005, 2007; Gargi et al., 2012; DiRienzo, 2014). Moreover, regardless of microbial source, all Cdts cause similar effects on a range of proliferating experimental target cells: cell cycle arrest and eventual cell death mediated by activation of the apoptotic cascade (Jinadasa et al., 2011). More recent observations suggest that Cdt is capable of inducing functional alterations in the absence of cell death in non-proliferating populations (Shenker et al., 2010, 2014).

Cdts are encoded by three genes, designated $c d t A, c d t B$, and $c d t C$, which are arranged as an operon which encodes three polypeptides which have been designated $\mathrm{CdtA}, \mathrm{CdtB}$, and $\mathrm{CdtC}$ with apparent molecular masses of 23-30, 28-32, and 19-20 kDa, respectively; these Cdt subunits form a heterotrimeric holotoxin (Pickett and Whitehouse, 1999; Shenker et al., 1999, 2000, 2001; De Rycke and Oswald, 2001; Thelastam and Frisan, 2004). Cdt toxin subunits are encoded by three marginally overlapping chromosomal genes $c d t A, c d t B$, and $c d t C$ (Pickett et al., 1994; Scott and Kaper, 1994; Okuda et al., 1995). However, Escherichia coli $c d t B$-III gene cluster is located on a transferable plasmid pVir (Pérès et al., 1997). In contrast to all other bacteria expressing Cdt, Salmonella enterica serotype Typhi (S. Typhi) lack genes encoding CdtA and CdtC (Haghjoo and Galán, 2004; Skyberg et al., 2006; Suez et al., 2013; Mezal et al., 2014; Figueiredo et al., 2015).

Although all Cdts exhibit similar activity, their amino acid sequences diverged among different bacterial species (Nesic et al., 2004). The CdtB sequences are more conserved among the Cdt-producing bacteria while the CdtA and CdtC subunits display a higher degree of variability (Cortes-Bratti et al., 2001; Lara-Tejero and Galán, 2001; Smith and Bayles, 2006). Bacteria from Escherichia genus are unique in the fact that five types of Cdts, termed EcolCdtB-I, EcolCdtB-II, EcolCdtBIII, EcolCdtB-IV, and EcolCdtB-V have been characterized so far based on CdtB subunit divergence. C. jejuni Cdt displays a relatively high amino acid sequence similarity to $E$. coli toxins and interacts with host cells in a similar way (Eshraghi et al., 2010). The Cdts from Haemophilus ducreyi and Aggregatibacter actinomycetemcomitans share only limited amino acid sequence homology with E. coli Cdt and were shown to have different requirements for intoxication and intracellular trafficking in host cells (Eshraghi et al., 2014). The $c d t B$ genes from seven Campylobacter species are conserved and can be amplified using common primers (Kamei et al., 2014).

In this review, we summarize our current understanding of the functional role of the subunits that comprise the Cdt holotoxin and, in particular, discuss the molecular mechanisms that underlay Cdt association with host cells and which contribute to the key events leading to toxicity. As Cdt has profound effects on multiple types of host cells, we discuss the evidence supporting a role for Cdt as a virulence factor. Specifically, we propose that $\mathrm{Cdt}$ is a unique and potent virulence factor capable of acting as a tri-perditious toxin that impairs host defenses by: (1) disrupting epithelial barriers; (2) suppressing acquired immunity; (3) promoting pro-inflammatory responses (summarized in Figure 1).

\section{Cdt SUBUNIT STRUCTURE AND FUNCTION \\ Cdt Subunits Responsible for Cell Association}

It is generally accepted that all three Cdt subunits, CdtA, $\mathrm{CdtB}$, and $\mathrm{CdtC}$, are required to achieve maximal toxic activity, regardless of the target cell. Thus, the holotoxin is believed to function as an $\mathrm{AB}_{2}$ toxin where the cell binding unit (B) is responsible for toxin binding to the cell surface and delivery of the active subunit (A) to intracellular compartments. In the context of $\mathrm{Cdt}$, binding activity is considered to be the result of cooperative activities of both the $\mathrm{CdtA}$ and $\mathrm{CdtC}$ subunits (reviewed in Gargi et al., 2012). Moreover, it has been proposed that these subunits share structural homology with lectin-like proteins and further, that fucose moieties might be involved in toxin association with the cell surface (Nesic et al., 2004; McSweeney and Dreyfus, 2005). In other studies, glycosphingolipids have been implicated as possible binding sites as inhibitors of glycosphingolipid synthesis reduce Cdt intoxication (Mise et al., 2005). It should be pointed out that in a more recent study in which Cdts from different microbial species were studied simultaneously, toxin-host interactions were shown not to depend upon fucosylated structures as well as $\mathrm{N}$ - and O-glycans (Eshraghi et al., 2010). These authors did, however, observe that several Cdts, including toxin prepared from A. actinomycetemcomitans, C. jejuni, and H. ducreyi, utilized membrane cholesterol; these results corroborated the findings of several other investigators (Guerra et al., 2005; Boesze-Battaglia et al., 2009; Zhou et al., 2012; Lai et al., 2013, 2015).

The ability of Cdt to specifically bind to cholesterol has been demonstrated utilizing both model membranes as well as live cells including both lymphocytes and macrophages (Boesze-Battaglia et al., 2006, 2009; Shenker et al., 2014). Moreover, cholesterol specific binding was shown to depend upon an amino acid sequence, the cholesterol recognition amino acid consensus sequence (CRAC), encoded within the CdtC subunit (Boesze-Battaglia et al., 2009). The CRAC site has been defined as: $-\mathrm{L} / \mathrm{V}-\left(\mathrm{X}_{1-5}\right)-\mathrm{Y}-\left(\mathrm{X}_{1-5}\right)-\mathrm{R} / \mathrm{K}$ - where $\mathrm{X}_{1-5}$ represents 1-5 residues of any amino acid. Furthermore, Boesze-Battaglia (Boesze-Battaglia et al., 2009) have demonstrated not only the presence of this site within the A. actinomycetemcomitans CdtC subunit, ${ }^{68}{ }^{6 I D Y K G K}{ }^{74}$-, but also that mutation of key CRAC residues results in reduced toxin binding, CdtB internalization, and toxicity (Boesze-Battaglia et al., 2009). More recently, a similar site has been identified for the CdtB subunit of the A. actinomycetemcomitans toxin (Boesze-Battaglia et al., 2015) 


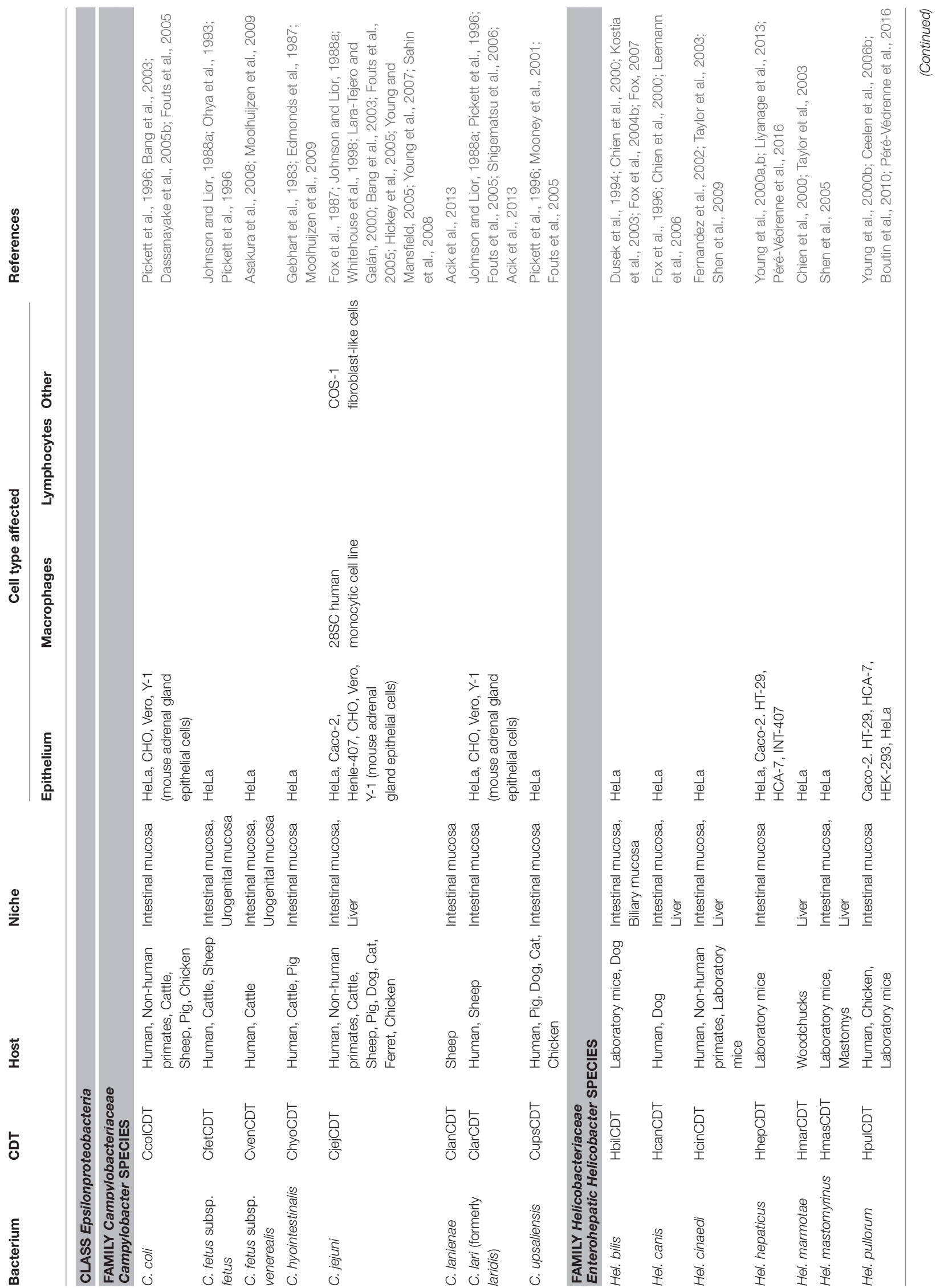




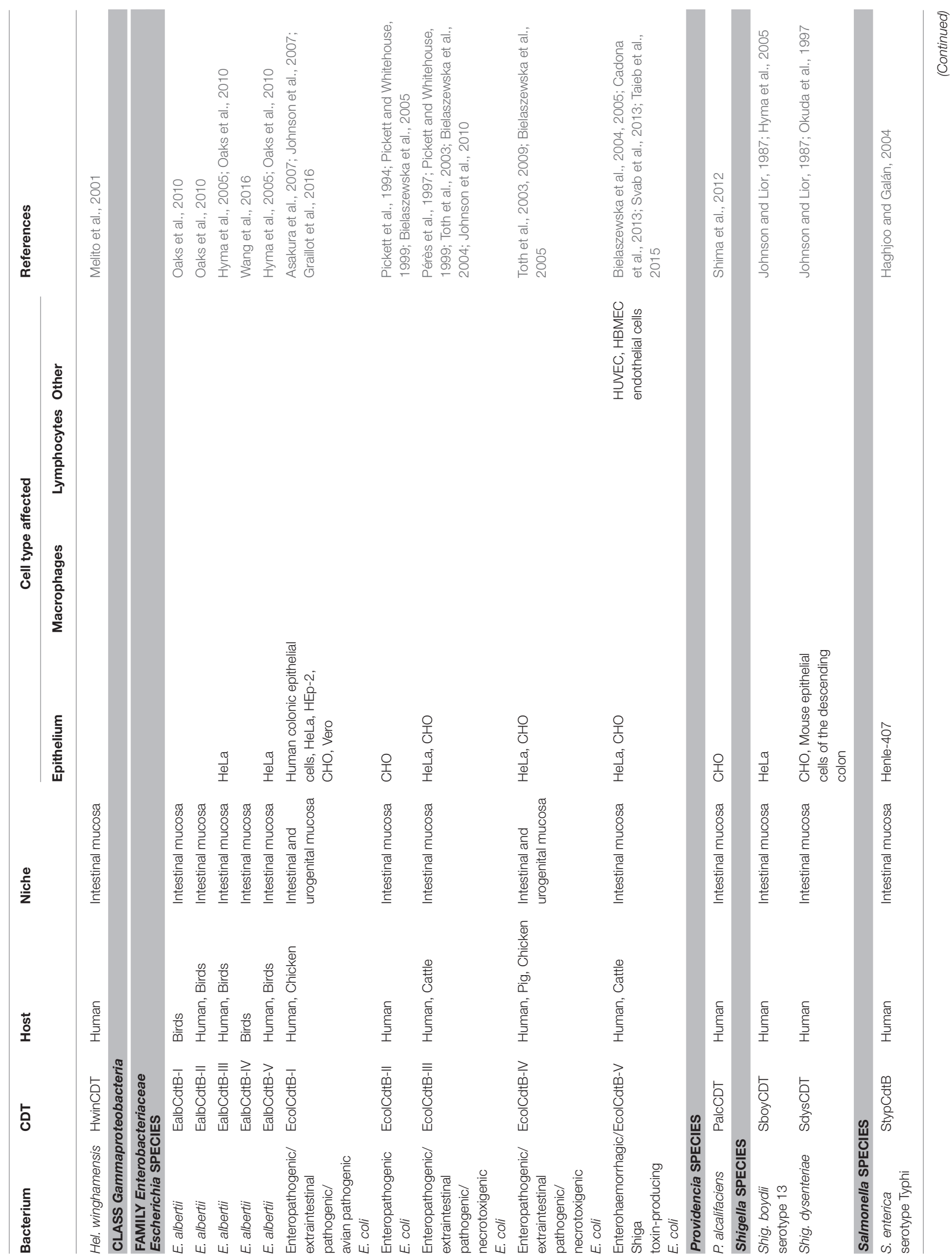




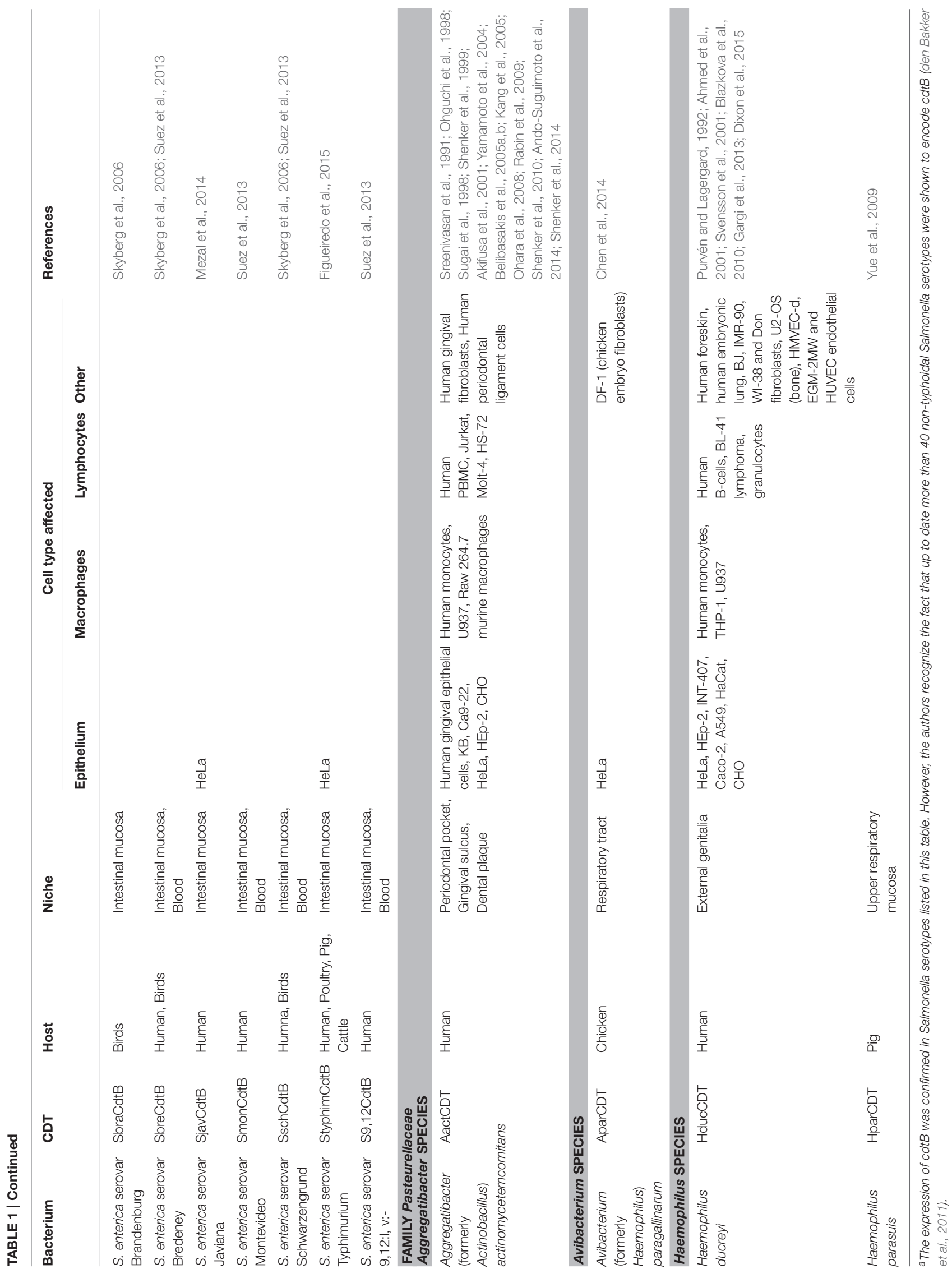




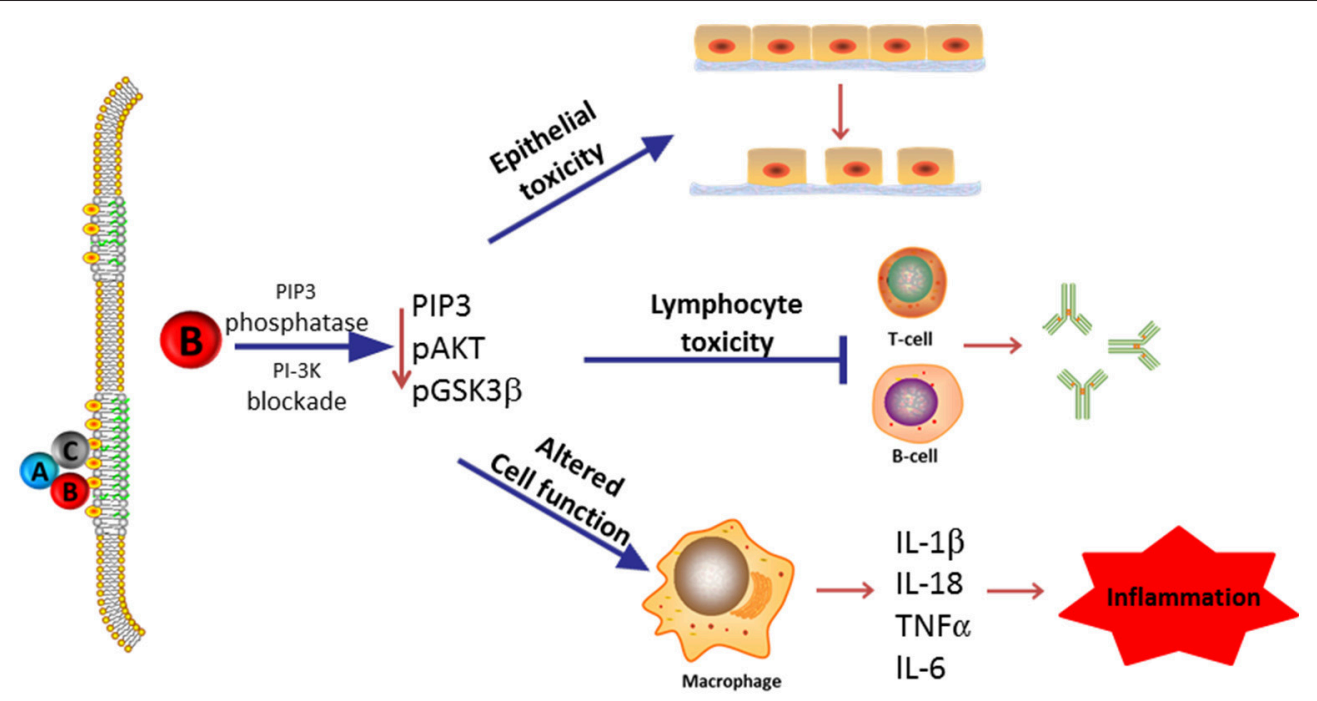

FIGURE 1 | Overview of Cdt's role as a virulence factor. Most Cdts are heterotrimeric $\mathrm{AB}_{2}$ toxins that are capable of affecting multiple cell types due to the ability of the binding (B) subunits to bind to cells via a common membrane moiety, cholesterol. Furthermore, the active (A) subunit, CdtB, functions as a PIP3 phosphatase and is therefore capable of inducing a blockade of a universally employed signaling cascade, PI-3K. We now propose that in its capacity as a virulence factor, Cdt functions as a tri-perditious toxin that is capable of impairing host defense in three ways: (1) induce cell cycle arrest and apoptosis in epithelial cells thereby altering epithelial barriers and facilitating infection by Cdt-producing pathogens; (2) induce cell cycle arrest and apoptosis in lymphocytes thereby impairing acquired immunity and promoting persistent infection; and (3) altering macrophage function leading to a pro-inflammatory response as a result of increased cytokine synthesis and inflammasome activation. Please note that we have not excluded the possibility that some Cdts and/or some cells may under some conditions be intoxicated as a result of CdtB associated DNase activity.

and is the focus of other papers in this section. It is also noteworthy that the presence of CRAC sites and utilization of cholesterol specific binding has been demonstrated for several proteins including the bacterial leukotoxin derived from $A$. actinomycetemcomitans, gp41 a transmembrane protein found in HIV, caveolin, apolipoproteins, benzodiazepine, G-protein coupled receptors, $\mathrm{Ca}^{++}$- and voltage-gated $\mathrm{K}^{+}$channels as well as the translocator protein, TSPO (Li and Papadopoulos, 1998; Vincent et al., 2002; Epand et al., 2005; Jamin et al., 2005; Jafurulla et al., 2011; Oddi et al., 2011; Singh et al., 2012; Brown et al., 2013; Lecanu et al., 2013).

It should be noted that not all investigators have observed that Cdts are dependent upon cholesterol. For instance, cholesterol loading experiments failed to alter cell susceptibility to C. jejuni (Eshraghi et al., 2010). Other investigators have reported that cholesterol depletion did not alter A. actinomycetemcomtans Cdt internalization (Damek-Poprawa et al., 2012). These findings are difficult to assess as the experimental protocol and/or cells utilized varied. For example, in some instances long exposure times to the cholesterol depleting agent, methyl- $\beta$ cyclodextrin, were employed; this has the risk of altering cell vitality. Furthermore, cholesterol repletion was not employed as a control to demonstrate both cholesterol specificity and verify that viability was not altered.

In addition to binding to cholesterol, it has been demonstrated that the Cdt holotoxin associates with cholesterol rich membrane microdomains, as demonstrated by co-localization with GM1 (Boesze-Battaglia et al., 2006). Disruption of lipid rafts by cholesterol depletion reduces toxin binding, $\mathrm{CdtB}$ internalization and cell susceptibility to Cdt intoxication (Boesze-Battaglia et al., 2009). Association of Cdt with lipid rafts may be critical to toxicity for several reasons. First, lipid microdomains have been shown to serve as a site of attachment for pathogens and provide a means to concentrate receptors for toxins and thereby increase binding affinity. Second, lipid microdomains play a key role in triggering internalization and may provide a means of entry for the CdtB subunit. Finally, lipid microdomains have been shown to also serve as signaling platforms; this would put the catalytic subunit, $\mathrm{CdtB}$, in close proximity to signaling cascades thereby facilitating their hijacking and involvement in mediating toxicity. It should be noted that Cdt association with lipid microdomains and its significance with respect to toxin binding, internalization and molecular mode of action are a topic of other publications in this topic area (Boesze-Battaglia et al., 2016; Lai et al., 2016).

\section{Molecular Mode of Action by Which the Active Cdt Subunit, CdtB, Induces Toxicity}

It is generally accepted that exposure of target cells to Cdt holotoxin leads to irreversible cell cycle arrest and cell death via apoptosis (Gelfanova et al., 1999; Cortes-Bratti et al., 2001; Shenker et al., 2001; Ohara et al., 2004). It should be noted that Cdt-induced cell cycle arrest typically involves arrest in the G2/M phase, although fibroblasts have been shown to undergo G1 arrest as well (Frisan et al., 2002). Another interesting phenomenon is that all cells are not susceptible to Cdt-induced toxicity (i.e., cell cycle arrest and apoptosis) and further that nondividing cells such as non-activated primary human lymphocytes, 
macrophages, and mast cells do not undergo apoptosis in the presence of Cdt (Shenker et al., 2001, 2010, 2014; Smith and Bayles, 2006). These results are not necessarily surprising as many microbial toxins exhibit cell specificity. However, in most instances, cell specificity is attributed to toxin binding to cell receptors that are unique to the susceptible population(s) and thereby restrict toxin association and internalization. However, as discussed earlier, Cdt binding to cells and subsequent CdtB internalization is dependent upon association and binding to cholesterol, a ubiquitous membrane component. Consistent with this finding, we have also demonstrated that Cdt binding and $\mathrm{CdtB}$ internalization occurs in cells that are both Cdtsusceptible as well as Cdt-resistant (Shenker et al., 2016a). Thus, restricted susceptibility to Cdt intoxication must be governed by a mechanism independent of binding and subunit internalization. In this regard, we propose that cell susceptibility to Cdt is directly related to the toxin's molecular mode of action.

\section{Evidence That Supports CdtB Functioning As a DNase}

The long-standing paradigm accounting for the molecular mechanism by which Cdt induces cell cycle arrest and ultimately apoptosis is based upon the active subunit's (CdtB) ability to function as a DNase (Lara-Tejero and Galán, 2000). The evidence in support of CdtB's ability to function as a DNase and thereby induce DNA damage has been the subject of numerous investigations and the focus of several recent review articles (Guerra et al., 2011b; Jinadasa et al., 2011; Grasso and Frisan, 2015; Taieb et al., 2016). Therefore, we only briefly summarize the evidence in support of this mode of action which is based upon the following three lines of investigation: (1) demonstration of in vitro DNase activity associated with CdtB; (2) nuclear localization of CdtB; and (3) activation of the DNA damage response (DDR).

Analysis of Cdt by X-ray crystallography demonstrates that $\mathrm{CdtB}$ exhibits structural similarity with a group of functionally unrelated metalloenzymes such as DNase I (Dlakić, 2000; Dlakic, 2001; Nesic et al., 2004; Yamada et al., 2006). Despite the lack of significant pairwise sequence identity, structural similarity was predicted on the basis of sensitive multiple sequence alignments as an extension of an earlier discovery of homology between the nucleases and bacterial sphingomyelinase (Matsuo et al., 1996). Analysis of CdtB indicates that its structure can be superimposed on eukaryote DNase I with an RMSD of 1.62 $\AA$ over $141 \mathrm{C} \alpha$ atoms. A group of six conserved residues that are found in catalytic sites of DNase I and CdtB superimpose with an RMSD of $0.34 \AA$ (see Figure 2 for the exact residue designation in CdtB). Direct evidence of DNase activity leading to strandbreaks and fragmentation of mammalian DNA has not been demonstrated to date. However, several investigators have shown that $\mathrm{CdtB}$ isolated from multiple bacteria is able to denature or relax supercoiled plasmid DNA in vitro (Elwell and Dreyfus, 2000a; Elwell et al., 2001; Mao and DiRienzo, 2002; Frisan et al., 2003; Nesic et al., 2004). Furthermore, mutations in putative catalytic amino acids have given rise

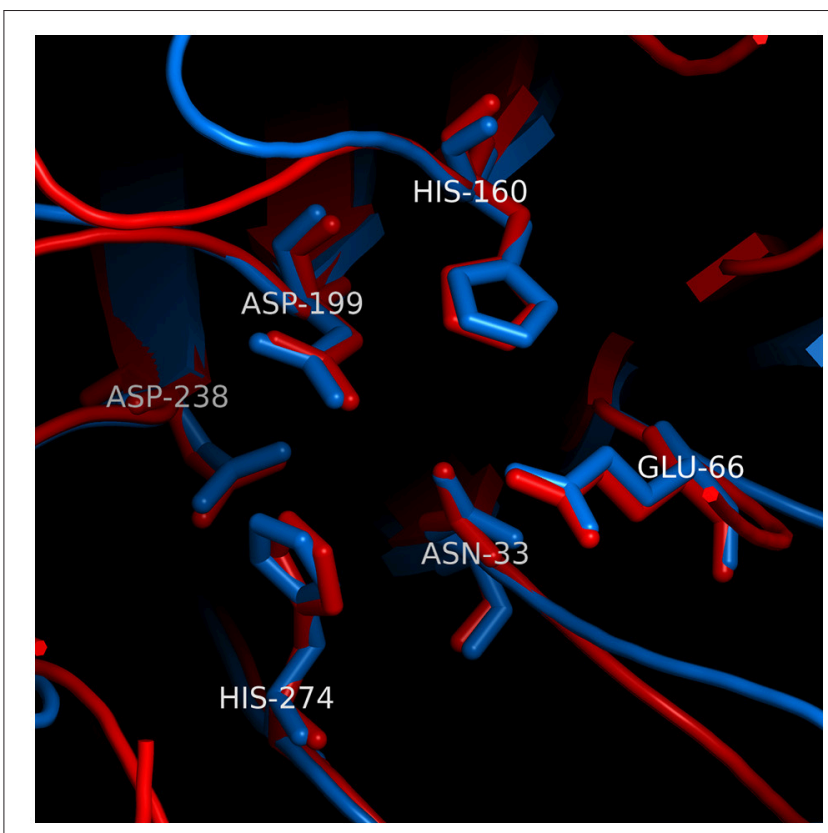

FIGURE 2 | Structural similarity between the active sites of CdtB and IP5P. The superposition was based on conserved residues in the active sites of CdtB [blue; PDB code 2f2f_B (Yamada et al., 2006)] and IP5P [red; PDB code 1i9z_A (Tsujishita et al., 2001)]. The two sets of 6 conserved residues are aligned well, with an RMSD of $0.26 \AA$. Residue numbers correspond to CdtB structure. Parts of superimposed structures were clipped out of viewing plane for clarity.

to proteins with both reduced enzymatic activity and toxicity (Elwell and Dreyfus, 2000b; Lara-Tejero and Galán, 2000; Nesic et al., 2004; Hu and Stebbins, 2006; Shenker et al., 2007, 2016a).

CdtB-mediated DNA damage requires that the active Cdt subunit translocate from the cell surface to the nucleus where it is able to encounter its enzymatic substrate. Several lines of investigation have been employed to demonstrate nuclear localization of CdtB. For example, purified E. coli CdtB was observed in the nucleus of cells following introduction of the subunit by electroporation as well as after transfection and ectopic expression (McSweeney and Dreyfus, 2004); likewise, Lara-Tejero and Galán (2000) demonstrated transient expression of $C$. jejuni $\mathrm{CdtB}$ led to nuclear localization. Moreover, E. coli and A. actinomycetemctomitans CdtB mutants lacking nuclear localization signals failed to accumulate in the nucleus and intoxicate cells (Nishikubo et al., 2003; McSweeney and Dreyfus, 2004). In a more recent study, Damek-Poprawa et al. (2012) demonstrated nuclear localization of $\mathrm{CdtB}$ following exposure of Chinese hamster ovary cells (CHO-K1) to A. actinomycetemcomitans toxin.

While there is a paucity of direct in vitro evidence that CdtB-associated DNase activity contributes to fragmentation of mammalian DNA, ample indirect data is available demonstrating that Cdt-treated cells exhibit signs of damage to cellular DNA. Evidence in support of CdtB-mediated DNA damage is derived 
from experiments that demonstrate DDR activation in Cdttreated cells. The DDR consists of multiple components such as sensors that detect strandbreaks, kinases and transcription factors that act as transducers and effector proteins that serve to delay cell cycle progression and promote DNA repair (Liu et al., 2016). For example, the presence of DNA strandbreaks has been shown to lead to formation of the MRN complex (Mre11, Rad50, and Nbs1) which in turn leads to recruitment and activation of the protein kinase, Ataxia telangiectasia mutated (ATM), and phosphorylation of the histone H2AX. Cdt's from $H$. ducreyi, C. jejuni, and E. coli have been shown to induce formation of the MRM complex and/or phosphorylation of $\mathrm{H} 2 \mathrm{AX}$ in HeLa cells, fibroblasts, epithelial cells, and lymphocytes (Li et al., 2002; Hassane et al., 2003; Bielaszewska et al., 2005; Liyanage et al., 2010; Dixon et al., 2015). Additionally, Cdt-treated cells exhibit activation of the G2 checkpoint in a manner that is consistent with other agents known to induce DNA damage and activation of the DDR. Specifically, several investigators have demonstrated that Cdt treated cells exhibit increased levels of the active kinase Chk2 along with hyperphosphorylation of both (inactive) CDC25 phosphatase and the cyclin-dependent kinase CDK1 (Sert et al., 1999; CortesBratti et al., 2001; Li et al., 2002; Sato et al., 2002; Yamamoto et al., 2004). In the absence of repair, activation of the G2 checkpoint should lead to apoptosis in addition to cell cycle arrest; an observation consistent with the known effects of Cdt. However, it has also been noted that if cells survive Cdt intoxication, CdtB-mediated DNA damage may contribute to genetic instability and thereby may promote carcinogenesis (Guidi et al., 2013).

It should be noted that in almost every instance, experiments demonstrating DNase activity, nuclear localization of $\mathrm{CdtB}$ as well as activation of the DDR were done under conditions of exposure to relatively high levels (microgram) of toxin as well as with "non-physiologic" routes of exposure. Interestingly, we and several other investigators have demonstrated that CdtB exhibits low DNase activity when compared with bovine DNase I $(<0.01 \%$, Elwell and Dreyfus, 2000a; Shenker et al., 2001; Haghjoo and Galán, 2004; Nesic et al., 2004) perhaps explaining the requirement for employing high toxin doses. Additionally, it should be noted that several of these studies failed to differentiate between DNA damage due to direct CdtB associated DNase activity and that due to indirect effects resulting from caspase mediated activation of endogenous DNase; the latter is supported by our own studies on lymphocytes and HeLa cells (Gelfanova et al., 1999; Shenker et al., 2001; Nalbant et al., 2003; Thelastam and Frisan, 2004). Specifically, inhibition of the apoptotic cascade by over expression of $\mathrm{Bcl}-2$ or with the use of a caspase- 3 inhibitor results in suppression of the DDR with no effect on Cdt-induced cell cycle arrest. Moreover, under conditions optimized to expose cells to the minimal amount of Cdt necessary to induce maximal G2 arrest within $24 \mathrm{~h}$ (and apoptosis at $48 \mathrm{~h}$ ), we were unable to demonstrate DDR activation in lymphoid cells at $4 \mathrm{~h}$. DDR activation could only be induced following longer exposures to higher Cdt concentrations for both lymphocytes and HeLa cells (Shenker et al., 2016a). These results collectively argue for DDR activation, at least in lymphocytes, to be the result of late events, and likely associated with enzymatic degradation of DNA due to activation of the apoptotic cascade.

\section{Evidence That CdtB Functions As a Phosphatidylinositol-3,4,5-Triphosphate (PIP3) Phosphatase}

As noted above, the bias in the literature supporting a role for CdtB associated DNase activity as the underlying mode of action function was based, in part, on structural homology with DNase I. This relationship obscures the fact that CdtB's protein fold and reaction mechanism are also shared with a number of metalloenzymes (Dlakić, 2000; Dlakic, 2001). CdtB structure can also be superimposed on inositol polyphosphate-5-phosphatase (IP5P), another member of this superfamily, with an RMSD of $1.63 \AA$ over $121 \mathrm{C} \alpha$ atoms, which is similar to that observed with DNase I. The six conserved residues in the catalytic site of CdtB (Yamada et al., 2006) and IP5P (Tsujishita et al., 2001) superimpose with an RMSD of $0.26 \AA$ (Figure 2), which is slightly better than the alignment of those same residues between CdtB and DNase I. This is not surprising since CdtB, IP5P, and DNase are all phosphoesterases (Dlakić, 2000; Dlakic, 2001); the specific function of each of these enzymes is largely dependent upon accommodation of substrates within their respective active site (Shenker et al., 2016a). Over the past several years, we have generated evidence for a new paradigm to account for the molecular mode of action by which $A$. actinomycetemcomitans $\mathrm{CdtB}$ intoxicates cells. Central to this mechanism is CdtB's ability to function as a lipid phosphatase similar to IP5P. As a result, Cdt is then able to perturb the critically important signaling pathway, the phosphoinositide 3-kinase (PI-3K) signaling pathway, that regulates cell survival, growth and a variety of functions that are cell type specific.

PIP3 is now recognized for its critical role in regulating cell growth, proliferation, and survival, among others (Kraub and Haucke, 2007; Sasaki et al., 2007; Buckler et al., 2008; Huang and Sauer, 2010). To be effective as a second messenger, PIP3 is maintained at low baseline levels which may increase rapidly in response to signals that typically originate at the plasma membrane leading to PI-3K activation. PIP3 levels are tightly regulated by three degradative enzymes: PTEN, SHIP1, and SHIP2 (Krystal, 2000; March and Ravichandran, 2002; Seminario and Wange, 2003). PTEN (ptase and tensin homolog deleted on chromosome ten), hydrolyzes PIP3 to PI-4,5-P 2 . SHIP1 (SH2-containing inositol phosphatase) and SHIP2 are inositol 5-phosphatases (IP5P); SHIP2 is ubiquitously expressed while SHIP1 is found in a limited subset of cells which includes immune cells. Both SHIP enzymes hydrolyze PIP3 to PI-3,4- $\mathrm{P}_{2}$ and inositol 1,3,4,5-tetrakisphosphate to inositol 1,3,4 triphosphate. The PI-3K/PIP3/Akt signaling pathway is regulated collectively by the action of these synthetic and degradative enzymes. Of particular relevance to Cdt toxicity, we have shown that the active Cdt subunit, CdtB, exhibits potent PIP3 phosphatase activity similar to that of SHIP.

In order to first establish a clear association between Cdtmediated toxicity and CdtB's ability to function as a PIP3 phosphatase, an extensive analysis of $\mathrm{CdtB}$ mutants was carried 
out. Mutants were designed to target residues predicted to be part of the active site and/or involved in substrate binding. Additional residues were targeted because they are conserved in both CdtB and IP5P but not in DNase I; other residues were targeted because they are conserved in IP5P and DNase I but not in CdtB. Analyses of this array of CdtB mutants clearly demonstrate a strong correlation between Cdt toxicity and retention of CdtB PIP3 phosphatase (Shenker et al., 2016a). Another key finding was that some mutants exhibited improved DNase activity; however this increase in enzymatic activity did not correlate with increased cytotoxicity suggesting that DNase function of $\mathrm{CdtB}$ is secondary to the lipid phosphatase function. This is consistent with the notion that a single enzyme is unlikely able to equally accommodate two substrates, such as DNA and lipid phosphates, as they significantly differ in both size and overall structure. Nonetheless, both molecules contain phosphate esters and are hydrolyzed, to some extent, by multiple enzymes such as those that comprise the superfamily that includes both CdtB and DNase I (Dlakić, 2000).

\section{CdtB Induces PI-3K Signaling Blockade}

Mutation analysis discussed above is consistent with the notion that $\mathrm{CdtB}$ perturbs the PI-3K/PIP3/Akt signaling pathway (Shenker et al., 2007, 2014; Boesze-Battaglia et al., 2015). More recent studies demonstrate that $\mathrm{CdtB}$ perturbs this signaling pathway within a few hours of exposure to Cdt; these changes include a decline in PIP3 levels and a concomitant increase in PI-3,4-P2, the enzymatic product of PIP3 degradation. Similar changes were observed for human peripheral blood mononuclear cells (HPBMC) activated by mitogen (Shenker et al., 2016a).

PI-3K activation leads to not only PIP3 production, but also phosphorylation of the critical downstream kinase, Akt; phosphorylation of Akt (pAkt) leads to its activation. Thus, it is noteworthy that Shenker et al. (2016a) observed that Cdt-treated lymphocytes not only exhibit PIP3 depletion, but also significant decreases in pAkt; this change in phosphorylation status was accompanied by a concomitant decrease in its kinase activity. A downstream target of pAkt is another kinase, GSK3 $\beta$. Activation of Akt typically leads to phosphorylation and inactivation of GSK3 $\beta$ (pGSK3 $\beta$ ). Indeed toxin treated cells were found to exhibit a reduction in the phosphorylation of GSK3 $\beta$; reduced pGSK3 $\beta$ was accompanied by an increase in its kinase activity. This observation is critical since GSK $3 \beta$, initially discovered as an inhibitor of glycogen synthase, has recently been implicated in the regulation of cell functions associated with inflammation, cell proliferation, and apoptosis, among others (Luo, 2009; Rayasam et al., 2009). It is noteworthy that pre-treatment of cells with GSK3 $\beta$ inhibitors reduced their susceptibility to Cdt intoxication; these results are consistent with a mode of action involving Cdtmediated PI-3K signaling blockade, suppression of cell growth and promotion of cell death (Buckler et al., 2008; Yuan and Cantley, 2008; Huang and Sauer, 2010).

CdtB associated lipid phosphatase activity and PI-3K blockade also contributes to toxicity in non-lymphoid cells. Under conditions optimized to induce cell cycle arrest at $24 \mathrm{~h}$, Shenker et al. (2016a) observed that Cdt holotoxin containing CdtB ${ }^{\mathrm{WT}}$ induced phosphorylation of $\mathrm{H} 2 \mathrm{AX}$ at $16 \mathrm{~h}$. These findings are consistent with results reported by other investigators following exposure to significantly higher concentrations of toxin ( $\mathrm{Li}$ et al., 2002; Fahrer et al., 2014). In contrast, substitution of CdtB wildtype with a $\mathrm{CdtB}$ mutant that was shown to retain phosphatase and no DNase activity $\left(\mathrm{CdtB}^{\mathrm{A} 163 \mathrm{R}}\right)$, failed to induce phosphorylation of $\mathrm{H} 2 \mathrm{AX}$; this mutant did induce G2 arrest as observed with $\mathrm{CdtB}^{\mathrm{WT}}$. These results clearly demonstrate that HeLa cells undergo Cdt-induced G2 arrest in the absence of CdtB-associated DNase activity and detectable DDR activation. It is noteworthy that these results are consistent with those of Sert et al. (1999) who reported that toxin-treated HeLa cells underwent G2 arrest in a manner that was independent of DNA damage. Interestingly, Shenker et al. (2016a) demonstrated that toxin comprised of CdtB mutants which retain DNase activity but deficient in PIP3 phosphatase activity lost the ability to induce HeLa cells to undergo G2 arrest; H2AX phosphorylation was also not observed in these cells. Cdt induced PI-3K blockade was further corroborated by the observation that GSK3 $\beta$ inhibitors could block toxin-induced G2 arrest in HeLa cells as described above for lymphoid cells (Shenker et al., 2016a).

Shenker et al. (2016a) did not rule out a possible role for DNase activity in mediating some aspects of Cdt toxicity. First, it is important to emphasize that PIP3 phosphatase activity has only been demonstrated for A. actinomycetemcomitans Cdt; it is possible that other Cdts are more dependent upon DNase activity to induce toxicity. Second, cells that exhibit resistance to Cdt and require exposure to high doses of $\mathrm{Cdt}$ in order to become intoxicated may indeed be responding to cellular alterations that are the result of CdtB associated DNase activity (Deng et al., 2001; Li et al., 2002; Guerra et al., 2011a). One argument against a primary role for Cdt-mediated PI-3K blockade is the observation that Saccharomyces cerevisiae are susceptible to Cdtinduced cell cycle arrest (Hassane et al., 2001; Matangkasombut et al., 2010); these cells do not synthesize PIP3. Nonetheless, $S$. cerevisiae do synthesize a myriad of phosphatidylinositol mono and di-phosphates; these phosphoinositides regulate many cell functions including growth and survival (Gardocki et al., 2005; Strahl and Thorner, 2007). To date there is no evidence demonstrating whether $\mathrm{CdtB}$ is able to alter any of these moieties in S. cerevisiae. Another area of controversy involves the link between the PI-3K pathway and regulation of cell size. This linkage lead Frisan et al. (2003) to suggest a critical role for PI-3K signaling in the development of cellular distension, a hallmark of Cdt toxicity; however, these authors did not provide evidence for PI-3K activation. It should also be noted that others have shown that there is no linkage between PI-3K signaling, cell size regulation and cell cycle arrest (Lee et al., 2007).

\section{EVIDENCE THAT Cdt EXPRESSION IS CRITICAL TO DISEASE}

As noted in Table 1, Cdts have been identified in a wide range of pathogenic species that infect a number of host tissues often in association with the development of significant inflammation. To date there is limited evidence that directly implicates Cdts 
as a virulence factor responsible for the molecular pathogenesis of disease in response to infection by Cdt-producing pathogens. Most evidence is circumstantial and based upon the presence of Cdt genes and/or protein in clinical isolates from pathogenic bacterial strains (summarized in Table 1). The identification of these Cdt-producing pathogens was initially based upon evaluation of bacterial extracts or supernatants for the presence of toxic activity and in some instances by genotyping for the presence of Cdt genes. More recently, several investigators have provided direct evidence suggesting that the pathogenicity of some pathogens is indeed linked to their ability to produce biologically active Cdt and thereby induce cytotoxic effects on host tissue. The evidence suggesting that $\mathrm{Cdt}$ is a crucial virulence factor is summarized in this section.

\section{E. coli Cdt}

The presence of Cdt in clinical isolates of E. coli 0128 and 055:K59:H4 was first reported in the 1980s' in association with gastroenteritis (Anderson et al., 1987; Johnson and Lior, 1988b). Although a causal relationship was not established, the authors suggested that Cdt may have encephalopathic potential based on clinical presentation of disease in a 3-year old patient. Since these initial observations, there have been numerous reports demonstrating the presence of $\mathrm{Cdt}$ in significant portions of clinical isolates of enteropathogenic E. coli (reviewed in Smith and Bayles, 2006); five cytolethal distending toxin sequence variants were detected in these E. coli strains (Clarke, 2001; Pickett et al., 2004; Hinenoya et al., 2009) and more recently, Shiga toxin-producing E. coli (Clarke, 2001; Janka et al., 2003; Bielaszewska et al., 2004). With respect to the latter, the authors suggested that Cdt-positive strains were significantly associated with clinical symptoms such as hemolytic uremic syndrome and watery diarrhea. In other studies, a putative role for Cdt in EPEC infections could not absolutely be determined because of the co-expression of other virulence factors by clinical isolates or in some instances, the low incidence rate of Cdt among isolates (Albert et al., 1996; Okeke et al., 2000). Additionally, Cdt-producing E. coli from serogroup 086:K61 were reported as a possible cause of mortality in birds (Foster et al., 1998). Culture supernatants from several of these strains were also tested on mammalian cell cultures and found to cause distinct morphological changes, cell cycle arrest and cell death implicating Cdt effects on vascular endothelium as well as on epithelial cells of the urinary and/or gastrointestinal tracts. The significance of these in vitro findings in the context of virulence and disease pathogenesis is discussed in the next section.

\section{Shigella spp. Cdt}

The production of Cdt was also described in Shigella dysenteriae type 2 and S. boydii type 7 strains. Similar to E. coli Cdts, Shigella Cdt was implicated in inflammatory responses of the gut (Johnson and Lior, 1988b). Okuda et al. (1997) provided the first in vivo experimental evidence of the diarrheagenicity of the S. dysenteriae Cdt in a suckling mouse model. Cdt-containing culture supernatant and partially purified Cdt preparations induced watery diarrhea. The incidence of loose/watery feces in mice subjected to $\mathrm{Cdt}$ was much higher as compared to animals given supernatants from Cdt-negative bacteria strains. The correlation between the amount of Cdt in the preparations and the diarrhea score, expressed as percentage of the diarrhea-positive animals in test groups, demonstrated the diarrheagenicity potential of Cdt.

\section{Campylobacter spp. Cdt}

A cytotoxic factor, later defined as Cdt, was detected in culture filtrates of numerous C. jejuni, C. coli, and C. laridis strains recognized as enteric pathogens in human diarrheal disease as well as $C$. fetus subs. fetus associated with bovine abortion. Exposure of epithelial cells to Campylobacter spp. Cdt resulted in cell elongation, distention, and subsequent death within 96-120 h. Homologous rabbit antitoxin neutralized Cdt activity (Johnson and Lior, 1988a; Mizuno et al., 1994). C. jejuni Cdt-induced HeLa and Caco-2 cell death following cell cycle arrest in early G2/M phase (Whitehouse et al., 1998; Jain et al., 2009).

Cell-free preparations from C. jejuni strains 81-176 and NCTC 11168 containing the CdtB subunit inactivated by insertional mutation had either much lower toxicity or were completely inactive in HeLa cell cytotoxicity assays. Following intragastric inoculation of adult severe immunocompromised (SCID) mice, C. jejuni CdtB-negative mutants showed similar intestinal colonization but greatly reduced invasiveness into blood, liver, and spleen as compared to isogenic wild-type strains. Moreover, descending colons of SCID mice were damaged in the presence of the active toxin (Purdy et al., 2000). Wild-type $C$. jejuni strain but not its Cdt-lacking isogenic mutant was capable of causing more progressive gastritis and proximal duodenitis in a mouse oral gavage model (Fox et al., 2004a) and in the suckling mouse model (Jain et al., 2008). It has been shown that Cdt-producing C. jejuni strains exhibit greater adherence to and invasion of epithelial cells than mutants lacking Cdt activity. Fox et al. (2004a) reported that production of Cdt may facilitate bacterial escape of immune surveillance by inducing cell cycle arrest and apoptosis in lymphocytes. Unlike the wildtype, C. jejuni mutant lacking Cdt activity was eliminated from immunocompetent mice; the bacteria persisted in NF-кBdeficient mice.

Cdt was also detected in sonicates prepared from multiple Helicobacter hepaticus strains, closely related to Campylobacter species. These toxin preparations were shown to display cytopathic effects on HeLa cells similar to C. jejuni Cdt (Young et al., 2000b). The production of biologically active Cdt, as confirmed by in vitro assays using HeLa, Caco-2, and HCA7 cells, was also reported in a number of other Helicobacter species, including human pathogens $H$. pullorum (Young et al., 2000b; Varon et al., 2014), H. canis (Chien et al., 2000), and $H$. cinaedi (Taylor et al., 2003). Interestingly, to date Cdt is the only known virulence factor present in $H$. hepaticus (Liyanage et al., 2010). Furthermore, a H. hepaticus isogenic mutant of the Cdt gene cluster had diminished capacity to induce lesions in the gut of C57BL/6 interleukin $10(-/-)$ mice in a model of inflammatory bowel disease. The animals infected with wild-type $H$. hepaticus developed severe mucosal hyperplasia accompanied by inflammation of the lamina propria, while the mice colonized with Cdt mutant exhibited only mild, patchy 
mucosal inflammation (Young et al., 2004; Pratt et al., 2006). Additionally, Ge et al. (2005) showed that the presence of biologically active Cdt is crucial for persistent colonization of $H$. hepaticus in cecum, colon and jejunum of out bread Swiss Webster mice.

\section{H. ducreyi Cdt}

$H$. ducreyi was shown to secrete a soluble cytotoxin that leads to the death of both HeLa and Hep-2 cells; it was further proposed that this toxin was a putative virulence factor contributing to the pathogenicity of this bacterium (Lagergård, 1992; Purvén and Lagergard, 1992; Lagergård and Purven, 1993; Purvén et al., 1995). This virulence factor was later identified as a product of the Cdt gene cluster. It should also be noted that in several studies, $64-89 \%$ of clinical isolates tested contained the Cdt genes (Purvén et al., 1995; Frisk et al., 2001). Culture supernatant obtained from a strain of $H$. ducreyi lacking the Cdt genes was unable to kill epithelial cells (Cope et al., 1997; Stevens et al., 1999). Expression of all three $H$. ducreyi recombinant Cdt subunits in E. coli was necessary to exert toxic effects on HEp-2 cell cultures (Frisk et al., 2001). Cortes-Bratti and co-investigators (Cortes-Bratti et al., 1999) demonstrated cell cycle arrest and epithelial cell death in the presence of $H$. ducreyi Cdt suggesting that the toxin may contribute to the development and chronic nature of the ulcerative lesions associated with chancroid.

Further, in vitro and in vivo studies provided compelling evidence for a role of Cdt as a bacterial virulence factor. Hemolysin-deficient $H$. ducreyi mutant producing Cdt elicited similar inhibitory and apoptotic effects on peripheral blood mononuclear cells and Jurkat cells as its isogenic parent (Gelfanova et al., 1999). However, when the $H$. ducreyi CdtA, CdtB, and/or CdtC subunit(s) were deleted, the toxin preparations exhibited lower (in case of cdtA mutant) or no cytotoxicity for HeLa cells. Surprisingly, no change in virulence of $H$. ducreyi Cdt mutants was observed in a temperaturedependent rabbit model (Lewis et al., 2001). Isogenic H. ducreyi $\mathrm{CdtC}$ mutant and its parent clone were also shown to be similarly virulent in pustule formation in the early stages of chancroid in human volunteers (Young et al., 2001). Nonetheless, purified H. ducreyi CdtA, CdtB, and CdtC, injected as a complex in rabbit skin, caused dose-dependent erythema and edema as well as inflammatory cell infiltration and dilatation of blood vessels. Individual protein subunits had no pathological effect on rabbit skin following intradermal injection (Wising et al., 2002).

\section{A. actinomycetemcomitans Cdt}

Cdt with amino acid sequence similar to $H$. ducreyi Cdt was also detected in Actinobacillus (currently Aggregatibacter) actinomycetemcomitans culture supernatants (Sugai et al., 1998; Ahmed et al., 2001; Yamano et al., 2003). All A. actinomycetemcomitans members of the restriction fragment length polymorphism (RFLP) group II cluster (DiRienzo and McKay, 1994), which was shown to be associated with the conversion in young children from periodontal health to localized aggressive periodontitis (LAP; Mayer et al., 1999), contained a complete $c d t$ gene locus (Mayer et al., 1999). The toxin was shown to cause cell distention and cell cycle arrest in HeLa cells. The combination of all three recombinant A. actinomycetemcomitans Cdt protein subunits expressed in E. coli was necessary to induce HEp-2 cell cycle arrest (Akifusa et al., 2001). Exposure of epithelial cells to individual subunits failed to block cell cycle progression.

Human lymphocytes were found to be exquisitely sensitive to A. actinomycetemcomitans Cdt; small quantities (picogram) of toxin were capable of inducing cell cycle arrest and apoptosis within 24 and 48 h, respectively (Shenker et al., 2001, 2004). Similar results were reported by Nalbant et al. (2003). In contrast, to the effect of Cdt on proliferating lymphoid cells, the toxin failed to kill human monocytes and macrophages (Shenker et al., 2014, 2015). Instead, exposure to Cdt resulted in the synthesis and release of pro-inflammatory cytokines. Likewise, Akifusa (Akifusa et al., 2001) demonstrated that Cdt induced IL-1 $\beta$, IL6 , and IL-8 cytokine production in human peripheral blood mononuclear cells (PBMCs).

The importance of $\mathrm{Cdt}$ as a potential A. actinomycetemcomitans virulence factor was underscored by its role in the induction of receptor activator of NF- $\kappa$ B ligand (RANKL) expression in human gingival fibroblasts and periodontal ligament cells. This is a critical finding as RANKL expression is associated with osteoclast differentiation and thereby contributes to regulation of bone resorption. Thus, the possibility exists that Cdt-induced expression of RANKL may be involved in the pathogenesis of periodontitis (Mogi, 2004). Purified recombinant $H$. ducreyi Cdt also induces RANKL expression in osteoclasts. Furthermore, pretreatment of $A$. actinomycetemcomitans wild-type extract with Cdt neutralizing antibody abolished RANKL expression (Belibasakis et al., 2005a). The detrimental effect of the A. actinomycetemcomitans Cdt on periodontal tissues was confirmed using an in vivo rat model. Topical application of Cdt to the gingival sulcus of rats resulted in junctional epithelial tissue abrasion. Interestingly, animals treated with both wild-type and mutated Cdt exhibited neutrophil infiltration. However, epithelial cell damage occurred only in rats treated with wild-type Cdt (Ohara et al., 2011). Damaging effects of wild-type A. actinomycetemcomitans Cdt on gingival epithelia were also detected in rat and human gingival explants (Damek-Poprawa et al., 2011, 2013).

\section{Salmonella enterica subsp. Enterica Serotype Typhi (S. Typhi) Cdt}

As noted earlier, the CdtB gene was also detected in S. Typhi (Parkhill et al., 2001; Haghjoo and Galán, 2004). While other Salmonella serovars cause self-limiting gastroenteritis, S. Typhi causes persistent and life-threatening systemic disease. S. Typhi produces a unique toxin, typhoid toxin, in which the active (A) unit is comprised of two subunits: CdtB and PltA, a homolog of the active subunit of pertussis toxin. Song et al. (2013) demonstrated that systemic administration of typhoid toxin into mice induced many of the symptoms commonly observed in the early stages of typhoid fever. Also, a non-typhoidal Salmonella enterica serovar Javiana was found to express Cdt; this organism is associated with gastrointestinal illnesses in humans, cattle, birds, and reptiles (Mezal et al., 2014). Biologically active S. 
Javiana Cdt was shown to increase invasiveness of the bacteria in HeLa cell cultures. These observations suggest a role for CdtB as an important virulence attribute of Salmonella. spp. (Mezal et al., 2014).

\section{Cdt FUNCTIONS AS A TRI-PERDITIOUS VIRULENCE FACTOR BY TARGETING HOST DEFENSES}

The role of a virulence factor is defined, in part, by key features such as its ability to associate with a specific cell(s) and its molecular mode of action. Taking into account that Cdt-producing bacteria typically infect mucocutaneous tissue, we now propose that $\mathrm{Cdt}$ contributes to microbial virulence by virtue of its ability to function as a tri-perditious toxin as it targets host defenses at three levels (see Figure 1): (1) promotion of infection by altering barrier protection through modulation of epithelial cell growth and survival, (2) promotion of inflammatory responses through activation of the inflammasome leading to cytokine maturation and release, and (3) impairment of acquired immunity and as a consequence diminished immune elimination by inhibiting $\mathrm{T}$ - and $\mathrm{B}$-cell proliferation and survival. In this section, we discuss the evidence that Cdt targets these three host systems.

Cdt is capable of intoxicating a wide range cells and/or cell lines, regardless of microbial source. Intoxication of proliferating cell populations is characterized by distinct morphological alterations, inhibition of cell growth most commonly associated with G2 arrest of the cell cycle and ultimately cell death resulting from activation of the apoptotic cascade (Jinadasa et al., 2011). In contrast, non-proliferating cells, such as macrophages, mast cells, and osteoclasts are resistant to Cdt-induced cell death; however, these cells are susceptible to Cdt-mediated alterations in cell function. The ability of a single toxin to affect multiple cell types is consistent with current understanding of the underlying mechanism of Cdt-host cell interactions which is dependent upon binding to cholesterol, a ubiquitous membrane component, as opposed to hijacking a unique receptor associated with a specific cell type. As noted earlier, Cdt from C. jejuni and $S$. Typhi are not dependent upon cholesterol binding. Moreover, the ability to intoxicate multiple cell types leading to different outcomes is also consistent with the proposed paradigm shift in which CdtB functions as a PIP3 phosphatase and targets the key PI-3K signaling pathway. As PI-3K is a signaling pathway commonly used by most cells to regulate a variety of functions, blockade of this pathway will lead to alterations involving a range of cell activities which are ultimately defined by the unique programming of each individual cell type. It should also be noted that hijacking of the PI-3K signaling cascade is also consistent with Cdt's association with cholesterol in the context of lipid rafts. These membrane moieties have been shown to serve as platforms for a number of signaling cascades in which substrates and critical components accumulate. It should also be noted that lipid rafts and sphingomyelin-controlled protein scaffolds are important for lipid signaling in cells; thus the observations of Carette et al. (2009) are critical as they demonstrate that cells deficient in sphingomyelin synthase are also resistant to Cdt intoxication. These results further suggest that lipid rafts are important for CdtB entry into cells.

\section{Cdt Impairs Epithelial Barriers}

Epithelial cells constitute the mechanical barrier between the host and an environment often teeming with microbes; thus, perturbation of protective epithelial layers exposes underlying tissues to bacteria and their products. As noted above, Cdtproducing bacteria identified to date are pathogens that exhibit an affinity to colonize mucocutaneous tissue such as oral, gastrointestinal, urinary, and respiratory tracts (Jinadasa et al., 2011). Moreover, the subsequent development of disease in these mucocutaneous niches is clearly the result of sustained infection and inflammation. For example, Cdt-producing Campylobacter, Escherichia, Helicobacter, Shigella, and Salmonella species account for a majority of food- and water-borne infectious diarrheal illnesses in humans (Tauxe, 1997; Ge et al., 2008; Jinadasa et al., 2011) and animals (Black et al., 1988; Dassanayake et al., 2005a; Johnson et al., 2007). Epithelial cells intoxicated with Cdt undergo G2 arrest leading to apoptosis (Ceelen et al., 2006a; Smith and Bayles, 2006; Liyanage et al., 2010, 2686/id). Cdt is also responsible for decreased intestinal epithelial cell adherence that results from alteration of actin cytoskeleton and disturbance of focal adhesion and microtubule network (Schulze et al., 1998; Varon et al., 2014).

In the oral cavity, highly proliferative primary human gingival epithelial cells (HGEC) are sensitive to the toxin produced by A. actinomycetemcomitans $\mathrm{Cdt}$ and exhibit a response similar to that observed with a Cdt-treated immortalized human oral vestibular epithelial cell line (GMSM-K; Kang et al., 2005; Kanno et al., 2005; Damek-Poprawa et al., 2011). Following intoxication, HGEC undergo rapid G2 arrest. As noted earlier, ex vivo experiments demonstrated that Cdt altered the integrity of the gingival epithelial barrier; damage included detachment of the keratinized outer layer, distention of spinous and basal cells in the oral epithelium, disruption of rete pegs, and dissolution of cell junctions (Damek-Poprawa et al., 2013). Likewise, the genital pathogen $H$. ducreyi, a well-established cause of a sexually transmitted chancroid (Abeck et al., 1997), has recently emerged as a major etiologic agent in chronic limb ulceration similar to yaws in the Pacific region and Africa. Infection with $H$. ducreyi occurred following trauma to the epithelial layer and Cdtinduced epithelial cell death was a contributing factor in slow healing of lesions (Lewis and Mitja, 2016).

\section{Cdt Impairs Acquired Immunity}

To date there have been few studies that assess immunity to Cdt following natural or experimental exposure. Nonetheless, studies on $A$. actinomycetemcomitans $\mathrm{Cdt}$, as well as the closely related Cdt from $H$. ducreyi, indicate that anti-Cdt responses in patients with LAP or chancroid who do harbor the respective pathogens, generally produce low levels of antibody. Moreover, in most instances where antibodies were detected, the incidence and potency of Cdt-neutralizing antibodies was low (Lagergård and Purven, 1993; Xynogala et al., 2009; Ando et al., 2010; Lundqvist et al., 2010). The authors concluded that either the holotoxin is 
not immunogenic or its ability to function as an immunotoxin interferes with the host's ability to respond to it as an immunogen. These authors also suggested that the inability to neutralize Cdt likely contributes to failure of the host's immune system to eliminate the microbe and thereby limit disease. Anecdotally, we have assessed > 20 LAP patient sera and 20\% were capable of toxin neutralization (unpublished data) and further, we have also generated $>100$ anti-Cdt monoclonal antibodies and found that only five were capable of toxin neutralization. In contrast, Wising et al. (2002) has demonstrated that immunization of rabbits with a toxoid prepared from Cdt results in a robust immune response capable of toxin neutralization. These results further support the notion the Cdt functions as an immunotoxin; although these latter observations could also be the result of novel epitopes becoming available when challenged with the toxoid. Finally, it should be noted that $S$. Typhi establishes persistent infection; this is an observation consistent with the action of an immunosuppressive toxin. As noted above, typhoid toxin is comprised of active subunits of both pertussis toxin and Cdt. It has been suggested that the immunomodulatory activity of the CdtB component of the typhoid toxin may be a contributing factor to this persistent infection (Haghjoo and Galán, 2004). Moreover, injection of typhoid toxin into mice induces many of the early symptoms associated with typhoid fever as well as a significant reduction in immune cells (Song et al., 2013).

Consistent with the discussion above, it is now wellestablished that lymphocytes, both $\mathrm{B}$ and $\mathrm{T}$, are among the most susceptible cells to Cdt. We first demonstrated that treatment of Jurkat cells and mitogen activated HPBMC with low levels (picogram) of $A$. actinomycetemcomitans Cdt resulted in inhibition of proliferation and G2 arrest within $24 \mathrm{hr}$; interestingly, these cells did not exhibit cellular distension as has been characterized for other cells (Shenker et al., 1999, 2000). Exposure to these same doses of Cdt resulted in apoptosis after 48 h. Nalbant et al. (2003) observed that Cdt holotoxin could also inhibit HPBMC proliferation; mutants lacking the $\mathrm{CdtB}$ subunit were deficient in this inhibitory effect. Likewise, Gelfanova et al. (1999) demonstrated that H. ducreyi Cdt also inhibited proliferation and induced apoptosis in these same cell populations. In 2001, Mooney et al. (2001) demonstrated that lysates of C. upsaliensis contained Cdt which could also induce G2 arrest in human T-cells. These findings have been confirmed by other investigators as well (Cortes-Bratti et al., 2001; Svensson et al., 2001; Sato et al., 2002). Xu et al. (2004) also demonstrated that monocyte-derived dendritic cells treated with $H$. ducreyi Cdt did not exhibit cytokine responses or support T-cell proliferation; these findings lead these authors to propose that the toxin not only impairs lymphocyte proliferation and survival, but may also interfere with early stages of the developing immune response.

\section{Cdt Promotes Pro-Inflammatory Macrophage Responses}

Innate immunity represents the first line of defense against microbial pathogens. A key component in the activation of innate immune responses involves Toll-like receptors (TLRs); recognition of microbial products by TLRs leads to the production of pro-inflammatory cytokines. In general, this proinflammatory response protects the host. However, excessive or prolonged release of pro-inflammatory cytokines may eventually turn this protective function to one that contributes to overt tissue damage. Conversion from a protective to destructive role is of particular relevance as many diseases associated with Cdt-producing pathogens involve persistent infection along with a robust inflammatory response. Periodontal disease, for example, is considered to be a bacterial-induced inflammatory disorder culminating in the destruction of tooth-supporting tissues. One form of periodontal disease, LAP, is associated with infection by Cdt-producing $A$. actinomycetemcomitans (Xynogala et al., 2009). Experimental and clinical investigations into the pathogenesis of LAP demonstrate the presence of high levels of pro-inflammatory cytokines within the periodontium (Ando et al., 2010). In addition to tissue damage which ultimately contributes to tooth loss, the degraded proteins along with hemin may serve the nutritional needs of the bacteria to further promote their growth and survival (Hajishengallis et al., 2012).

As noted above, there is general consensus that macrophage survival is not altered by Cdts (Svensson et al., 2001; Shenker et al., 2014); however, macrophages are indeed susceptible to Cdt intoxication. Cdt has been shown to perturb PI-3K signaling in human monocytes and macrophages derived from the THP1 cell line. Specifically, Cdt treatment resulted in decreases in Akt and GSK3 $\beta$ phosphorylation; concomitant alterations in kinase activity was observed with lymphocytes (Shenker et al., 2014). Exposure to Cdt did not lead to macrophage death; however, the toxin did induce a pro-inflammatory cytokine response characterized by increased expression and release of IL- $1 \beta$, IL- $18, \mathrm{TNF} \alpha$, and IL- 6 . Interestingly, Cdt also augmented the pro-inflammatory cytokine response stimulated by TLR-2, -3 , or -4 agonists. These findings are consistent with CdtB-mediated PI-3K bockade, GSK3 $\beta$ activation and $\mathrm{NF}-\kappa \mathrm{B}$ activation; the latter is known to lead to increased expression of pro-inflammatory cytokines (Arbibe et al., 2000; Guha and Mackman, 2002; Hazeki et al., 2007; Molnarfi et al., 2007; Brown et al., 2010; Antoniv and Ivashkiv, 2011).

Release of mature IL- $1 \beta$ and IL-18 is known to be dependent upon caspase- 1 activation; maturation of caspase- 1 is dependent upon the activation of inflammasomes. Indeed, the Cdtinduced pro-inflammatory response was also observed to be dependent upon activation of the NLRP3 inflammasome. Shenker et al. (2015) have demonstrated Cdt-mediated inflammasome activation is dependent upon toxin-induced increases in extracellular ATP, activation of the purinergic receptor, $\mathrm{P}_{2} \mathrm{X}_{7}$ and $\mathrm{K}^{+}$efflux. It should also be noted that Belibasakis and Johansson (2012) have shown that treatment of human monocytes with A. actinomycetemcomitans leads to increased expression of NLRP3; however, they reported that this effect was not dependent upon Cdt. The authors did not indicate if inflammasome activation occurred in toxin treated cells or whether mature cytokine was secreted. 


\section{SUMMARY}

In this review, we have addressed a key issue relevant to the role of Cdt as a virulence factor. Many cells have been shown to be susceptible to Cdt intoxication; however, it should be noted that cells do exhibit differential susceptibility to Cdt in terms of absolute sensitivity. Specifically, lymphocytes and possibly epithelial cells represent the highly sensitive side of the spectrum requiring picogram to nanogram quantities of $\mathrm{Cdt}$, while $\mathrm{HeLa}$ cells and fibroblasts represent the least sensitive side typically requiring microgram quantities of toxin; macrophages exemplify cells of moderate sensitivity requiring nanogram quantities. We propose that differential cell sensitivity to Cdt reflects variance in the dependence of cells on PI-3K signaling for cell survival, growth and/or cell function. Moreover, toxin susceptibility is likely influenced by baseline levels of intracellular PIP3 which reflect the state of activity of this signaling pathway. Indeed, we have previously demonstrated that lymphoid susceptibility to Cdt correlates with baseline PIP3 levels; lymphoid cells with high levels of PIP3 and active PI-3K signaling exhibit heightened susceptibility to Cdt vs. those with low levels of the lipid second messenger and relatively inactive signaling exhibited reduced sensitivity (Shenker et al., 2016b). In conclusion, we propose that Cdt functions as a tri-perditious virulence factor as it targets host defenses in three ways: (1) altering barrier protection (via epithelial toxicity) thereby promoting infection: (2) impairment of acquired immunity (via lymphocyte toxicity) reducing immune elimination; and (3) promotion

\section{REFERENCES}

Abeck, D., Freinkel, A. L., Korting, H. C., Szeimis, R. M., and Ballard, R. C. (1997). Immunohistochemical investigations of genital ulcers caused by Haemophilus ducreyi. Int. J. STD AIDS 8, 585-588. doi: 10.1258/0956462971920839

Acik, M. N., Karahan, M., Ongor, H., and Cetinkaya, B. (2013). Investigation of virulence and cytolethal distending toxin genes in Campylobacter spp. isolated from sheep in Turkey. Foodborne Pathog. Dis. 10, 589-594. doi: 10.1089/fpd. 2012.1447

Ahmed, H. J., Svensson, L. A., Cope, L. D., Latimer, J. L., Hansen, E. J., Ahlman, K., et al. (2001). Prevalence of cdtABC genes encoding cytolethal distending toxin among Haemophilus ducreyi and Actinobacillus actinomycetemcomitans strains. J. Med. Microbiol. 50, 860-864. doi: 10.1099/0022-1317-50-10-860

Akifusa, S., Poole, S., Lewthwaite, J., Henderson, B., and Nair, S. P. (2001). Recombinant Actinobacillus actinomycetemcomitans cytolethal distending toxin proteins are required to interact to inhibit human cell cycle progression and to stimulate human leukocyte cytokine synthesis. Infect. Immun. 69, 5925-5930. doi: 10.1128/IAI.69.9.5925-5930.2001

Albert, M. J., Faruque, S. M., Faruque, A. S., Bettelheim, K. A., Keogi, P. K., Bhuiyan, N. A., et al. (1996). Controlled study of cytolethal distending toxinproducing Escherichia coli infections in Bangladeshi children. J. Clin. Microbiol. 34, 717-719.

Anderson, J. D., MacNab, A. J., Gransden, W. R., Damm, S. M., Johnson, W. M., and Lior, H. (1987). Gastroenteritis and encephalopathy associated with a strain of Escherichia coli 055:K59:H4 that produced a cytolethal distending toxin. Pediatr. Infect Dis. J 6, 1135-1136. doi: 10.1097/00006454-19871200000015

Ando, E. S., De-Gennaro, L. A., Faveri, M., Feres, M., DiRienzo, J. M., and Mayer, M. P. (2010). Immune response to cytolethal distending toxin of Aggregatibacter actinomycetemcomitans in periodontitis patients. J. Periodontal Res. 45, 471-480. doi: 10.1111/j.1600-0765.2009.01260.x of inflammation (cytokine expression by macrophages). Cdt's ability to mount a three-pronged attack against host defenses is facilitated by its unique ability to utilize cholesterol, a ubiquitous moiety to bind to plasma membranes and to target cell homeostasis and function through a signaling pathway common to all cells. It is important to point out that lipid phosphatase activity has only been demonstrated for CdtB from A. actinomycetemcomitans. However, based upon sequence homology, we believe that $\mathrm{CdtB}$ from $H$. ducreyi would exhibit similar activity. Moreover, since all CdtB's analyzed to date exhibit relatively poor DNase activity, it is reasonable to expect that toxin produced by other bacteria will act through a similar mode of action. Thus, we anticipate that future studies will demonstrate that CdtB's from other Cdt producing pathogens will exhibit robust PIP3 phosphatase activity similar to that of $A$. actinomycetemomitans CdtB.

\section{AUTHOR CONTRIBUTIONS}

The ideas and concepts presented in this review are the synthesis and compilation of the ideas developed from all four authors. Each author contributed text and/or figures to the manuscript. Each author had significant input into this manuscript.

\section{ACKNOWLEDGMENTS}

This work was supported by the National Institutes of Health grants DE06014 (BS), DE023071 (BS), and DE022465 (KB).

Ando-Suguimoto, E. S., da Silva, M. P., Kawamoto, D., Chen, C., DiRienzo, J. M., and Mayer, M. P. (2014). The cytolethal distending toxin of Aggregatibacter actinomycetemcomitans inhibits macrophage phagocytosis and subverts cytokine production. Cytokine 66, 46-53. doi: 10.1016/j.cyto.2013. 12.014

Antoniv, T. T., and Ivashkiv, L. B. (2011). Interleukin-10-induced gene expression and suppressive function are selectively modulated by the PI3K-Akt-GSK3 pathway. Immunology 132, 567-577. doi: 10.1111/j.1365-2567.2010.03402.x

Arbibe, L., Mira, J. P., Teusch, N., Kline, L., Guha, M., Mackman, N., et al. (2000). Toll-like receptor 2-mediated NF-кB activation requires a Rac1-dependent pathway. Nat. Immunol. 1, 533-540. doi: 10.1038/82797

Asakura, M., Hinenoya, A., Alam, M. S., Shima, K., Zahid, S. H., Shi, L., et al. (2007). An inducible lambdoid prophage encoding cytolethal distending toxin (Cdt-I) and a type III effector protein in enteropathogenic Escherichia coli. Proc. Natl. Acad. Sci. U.S.A 104, 14483-14488. doi: 10.1073/pnas.0706695104

Asakura, M., Samosornsuk, W., Hinenoya, A., Misawa, N., Nishimura, K., Matsuhisa, A., et al. (2008). Development of a cytolethal distending toxin (cdt) gene-based species-specific multiplex PCR assay for the detection and identification of Campylobacter jejuni, Campylobacter coli and Campylobacter fetus. FEMS Immunol. Med. Microbiol. 52, 260-266. doi: 10.1111/j.1574-695X. 2007.00369.x

Bang, D. D., Nielsen, E. M., Scheutz, F., Pedersen, K., Handberg, K., and Madsen, M. (2003). PCR detection of seven virulence and toxin genes of Campylobacter jejuni and Campylobacter coli isolates from Danish pigs and cattle and cytolethal distending toxin production of the isolates. J. Appl. Microbiol. 94, 1003-1014. doi: 10.1046/j.1365-2672.2003.01926.x

Belibasakis, G. N., Johansson, A., Wang, Y., Chen, C., Kalfas, S., and Lerner, U. H. (2005a). The cytolethal distending toxin induces receptor activator of NF- $\kappa \mathrm{B}$ ligand expression in human gingival fibroblasts and periodontal ligament cells. Infect. Immun. 73, 342-351. doi: 10.1128/IAI.73.1.342-35 1.2005 
Belibasakis, G. N., Johansson, A., Wang, Y., Chen, C., Lagergard, T., Kalfas, S., et al. (2005b). Cytokine responses of human gingival fibroblasts to Actinobacillus actinomycetemcomitans cytolethal distending toxin. Cytokine 30, 56-63. doi: 10 . 1016/j.cyto.2004.11.008

Belibasakis, G. N., and Johansson, A. (2012). Aggregatibacter actinomycetemcomitans targets NLRP3 and NLRP6 inflammasome expression in human mononuclear leukocytes. Cytokine 59, 124-130. doi: 10.1016/j.cyto. 2012.03.016

Bielaszewska, M., Fell, M., Greune, L., Prager, R., Fruth, A., Tschäpe, H., et al. (2004). Characterization of cytolethal distending toxin genes and expression in shiga toxin-producing Escherichia coli strains of non-O157 serogroups. Infect. Immun. 72, 1812-1816. doi: 10.1128/IAI.72.3.1812-1816.2004

Bielaszewska, M., Sinha, B., Kuczius, T., and Karch, H. (2005). Cytolethal distending toxin from Shiga toxin-producing Escherichia coli 0157 causes irreversible G2/M arrest, inhibition of proliferation, and death of human endothelial cells. Infect. Immun. 73, 552-562. doi: 10.1128/IAI.73.1.552-562. 2005

Black, R. E., Levine, M. M., Clements, M. L., Hughes, T. P., and Blaser, M. J. (1988). Experimental Campylobacter jejuni infection in humans. J. Infect. Dis. 157, 472-479. doi: 10.1093/infdis/157.3.472

Blazkova, H., Krejcikova, K., Moudry, P., Frisan, T., Hodny, Z., and Bartek, J. (2010). Bacterial intoxication evokes cellular senescence with persistent DNA damage and cytokine signaling. J. Cell. Mol. Med. 14, 357-367. doi: 10.1111/j. 1582-4934.2009.00862.x

Boesze-Battaglia, K., Alexander, D., Dlakić, M., and Shenker, B. J. (2016). A journey of cytolethal distending toxins through cell membranes. Front. Cell. Infect. Microbiol. 6:81. doi: 10.3389/fcimb.2016.00081

Boesze-Battaglia, K., Besack, D., McKay, T., Zekavat, A., Otis, L., Jordan-Sciutto, K., et al. (2006). Cholesterol-rich membrane microdomains mediate cell cycle arrest induced by Actinobacillus actinomycetemcomitans cytolethal distending toxin. Cell. Microbiol. 8, 823-836. doi: 10.1111/j.1462-5822.2005.00669.x

Boesze-Battaglia, K., Brown, A., Walker, L., Besack, D., Zekavat, A., Wrenn, S., et al. (2009). Cytolethal distending toxin-induced cell cycle arrest of lymphocytes is dependent upon recognition and binding to cholesterol. J. Biol. Chem. 284, 10650-10658. doi: 10.1074/jbc.M809094200

Boesze-Battaglia, K., Walker, L. P., Zekavat, A., Dlakic, M., Scuron, M. D., Nygren, P., et al. (2015). The Aggregatibacter actinomycetemcomitans cytolethal distending toxin active subunit $\mathrm{CdtB}$ contains a cholesterol recognition sequence required for toxin binding and subunit internalization. Infect. Immun. 83, 4042-4055. doi: 10.1128/IAI.00788-15

Boutin, S. R., Shen, Z., Roesch, P. L., Stiefel, S. M., Sanderson, A. E., Multari, H. M., et al. (2010). Helicobacter pullorum outbreak in C57BL/6NTac and C3H/HeNTac barrier-maintained mice. J. Clin. Microbiol. 48, 1908-1910. doi: 10.1128/JCM.02531-09

Brown, A. C., Balashova, N. V., Epand, R. M., Epand, R. F., Bragin, A., Kachlany, S. C., et al. (2013). Aggregatibacter actinomycetemcomitans leukotoxin utilizes a cholesterol recognition amino acid consensus site for membrane association. J. Biol. Chem. 288, 23607-23621. doi: 10.1074/jbc.M113.486654

Brown, J., Wang, H., Hajishengallis, G. N., and Martin, M. (2010). TLR-signaling networks: an integration of adaptor molecules, kinases, and cross-talk. J. Dent. Res. 90, 417-427. doi: 10.1177/0022034510381264

Buckler, J. L., Liu, X., and Turka, L. A. (2008). Regulation of T-cell responses by PTEN. Immunol. Rev. 224, 239-248. doi: 10.1111/j.1600-065X.2008.00650.x

Cadona, J. S., Bustamante, A. V., Parma, A. E., Lucchesi, P. M., and Sanso, A. M. (2013). Distribution of additional virulence factors related to adhesion and toxicity in Shiga toxin-producing Escherichia coli isolated from raw products in Argentina. Lett. Appl. Microbiol. 56, 449-455. doi: 10.1111/lam.12067

Carette, J., Guimaraes, C., Varadarajan, M., Park, A., Wuethrich, I., Godarova, A., et al. (2009). Haploid genetic screens in human cells identify host factors used by pathogens. Science 236, 1231-1234. doi: 10.1126/science.1178955

Ceelen, L. M., Decostere, A., Ducatelle, R., and Haesebrouck, F. (2006a). Cytolethal distending toxin generates cell death by inducing a bottleneck in the cell cycle. Microbiol. Res. 161, 109-120. doi: 10.1016/j.micres.2005.04.002

Ceelen, L. M., Haesebrouck, F., Favoreel, H., Ducatelle, R., and Decostere, A. (2006b). The cytolethal distending toxin among Helicobacter pullorum strains from human and poultry origin. Vet. Microbiol. 113, 45-53. doi: 10.1016/j. vetmic.2005.10.020
Chen, Y. C., Tan, D. H., Shien, J. H., Hsieh, M. K., Yen, T. Y., and Chang, P. C. (2014). Identification and functional analysis of the cytolethal distending toxin gene from Avibacterium paragallinarum. Avian Pathol. 43, 43-50. doi: 10.1080/ 03079457.2013.861895

Chien, C. C., Taylor, N. S., Ge, Z., Schauer, D. B., Young, V. B., and Fox, J. G. (2000). Identification of cdtB homologues and cytolethal distending toxin activity in enterohepatic Helicobacter spp. J. Med. Microbiol. 49, 525-534. doi: 10.1099/ 0022-1317-49-6-525

Clarke, S. C. (2001). Diarrhoeagenic Escherichia coli-an emerging problem? Diagn. Microbiol. Infect. Dis. 41, 93-98. doi: 10.1016/S0732-8893(01)00303-0

Cope, L. D., Lumbley, S., Klesney-Tait, J., Stevens, M., Johnson, L., Purven, M., et al. (1997). A diffusible cytotoxin of Haemophilus ducreyi. Proc. Natl. Acad. Sci. U.S.A. 94, 4056-4061. doi: 10.1073/pnas.94.8.4056

Cortes-Bratti, X., Chaves-Olarte, E., Lagergård, T., and Thiagalingam, S. (1999). The cytolethal distending toxin from the chancroid bacterium Haemophilus ducreyi induces cell cycle arrest in the G2 phase. J. Clin. Invest. 103, 107-115. doi: $10.1172 /$ JCI3831

Cortes-Bratti, X., Karlsson, C., Lagergård, T., Thelastam, M., and Frisan, T. (2001). The Haemophilus ducreyi cytolethal distending toxin induces cell cycle arrest and apoptosis via the DNA damage checkpoint pathways. J. Biol. Chem. 276, 5296-5302. doi: 10.1074/jbc.M008527200

Damek-Poprawa, M., Haris, M., Volgina, A., Korostoff, J., and DiRienzo, J. M. (2011). Cytolethal distending toxin damages the oral epithelium of gingival explants. J. Dent. Res. 90, 874-879. doi: 10.1177/0022034511403743

Damek-Poprawa, M., Jang, J. Y., Volgina, A., Korostoff, J., and DiRienzo, J. M. (2012). Localization of Aggregatibacter actinomycetemcomitans cytolethal distending toxin subunits during intoxication of live cells. Infect. Immun. 80, 2761-2770. doi: 10.1128/IAI.00385-12

Damek-Poprawa, M., Korostoff, J., Gill, R., and DiRienzo, J. M. (2013). Cell junction remodeling in gingival tissue exposed to a microbial toxin. J. Dent. Res. 92, 518-523. doi: 10.1177/0022034513486807

Dassanayake, R. P., Griep, M. A., and Duhamel, G. E. (2005a). The cytolethal distending toxin $\mathrm{B}$ sub-unit of Helicobacter hepaticus is a $\mathrm{Ca}^{2+}$ - and $\mathrm{Mg}^{2+}$ dependent neutral nuclease. FEMS Microbiol. Lett. 251, 219-225. doi: 10.1016/ j.femsle.2005.08.005

Dassanayake, R. P., Zhou, Y., Hinkley, S., Stryker, C. J., Plauche, G., Borda, J. T. et al. (2005b). Characterization of cytolethal distending toxin of Campylobacter species isolated from captive macaque monkeys. J. Clin. Microbiol. 43, 641-649. doi: 10.1128/JCM.43.2.641-649.2005

De Rycke, J., and Oswald, E. (2001). Cytolethal distending toxin (CDT): a bacterial weapon to control host cell proliferation? FEMS Microbiol. Lett. 203, 141-148. doi: 10.1111/j.1574-6968.2001.tb10832.x

den Bakker, H. C., Moreno Switt, A. I., Govoni, G., Cummings, C. A., Ranieri, M. L., Degoricija, L., et al. (2011). Genome sequencing reveals diversification of virulence factor content and possible host adaptation in distinct subpopulations of Salmonella enterica. BMC Genomics 12:425. doi: 10.1186/1471-2164-12-425

Deng, K., Latimer, J. L., Lewis, D. A., and Hansen, E. J. (2001). Investigation of the interaction among the components of the cytolethal distending toxin of Haemophilus ducreyi. Biochem. Biophys. Res. Commun. 285, 609-615. doi: 10. 1006/bbrc. 2001.5223

DiRienzo, J. M. (2014). Breaking the gingival epithelia barrier: role of the Aggregatibacter actinomycetemcomitans cytolethal distending toxin in oral infectious disease. Cells 3, 476-499. doi: 10.3390/cells3020476

DiRienzo, J. M., and McKay, T. L. (1994). Identification and characterization of genetic cluster groups of Actinobacillus actinomycetemcomitans isolated from the human oral cavity. J. Clin. Microbiol. 32, 75-81.

Dixon, S. D., Huynh, M. M., Tamilselvam, B., Spiegelman, L. M., Son, S. B., Eshraghi, A., et al. (2015). Distinct roles for CdtA and CdtC during intoxication by cytolethal distending toxins. PLOS ONE 10:e0143977. doi: 10.1371/journal. pone. 0143977

Dlakić, M. (2000). Functionally unrelated signalling proteins contain a fold similar to $\mathrm{Mg}^{2+}$-dependent endonucleases. Trends Biochem. Sci. 25, 272-273. doi: 10. 1016/S0968-0004(00)01582-6

Dlakic, M. (2001). Is CdtB a nuclease or a phosphatase? Science 291, 547. doi: 10. $1126 /$ science.291.5504.547a

Dusek, D. M., Progulske-Fox, A., and Brown, T. A. (1994). Systemic and mucosal immune responses in mice orally immunized with avirulent Salmonella 
typhimurium expressing a cloned Porphyromonas gingivalis hemagglutinin. Infect. Immun. 62, 1652-1657.

Edmonds, P., Patton, C. M., Griffin, P. M., Barrett, T. J., Schmid, G. P., Baker, C. N., et al. (1987). Campylobacter hyointestinalis associated with human gastrointestinal disease in the United States. J. Clin. Microbiol. 25, 685-691.

Elwell, C. A., and Dreyfus, L. A. (2000a). DNase I homologous residues in CdtB are critical for cytolethal distending toxin-mediated cell cycle arrest. Mol. Microbiol. 37, 952-963. doi: 10.1046/j.1365-2958.2000.02070.x

Elwell, C. A., and Dreyfus, L. A. (2000b). "Mutational analysis of the Escherichia coli cytolethal distending toxin," in 100th General Meeting of the Society for Microbiology. P65 Abstract B109.

Elwell, C., Chao, K., Patel, K., and Dreyfus, L. (2001). Escherichia coli CdtB mediates cytolethal distending toxin cell cycle arrest. Infect. Immun. 69, 3418-3422. doi: 10.1128/IAI.69.5.3418-3422.2001

Epand, R. M., Sayer, B. G., and Epand, R. F. (2005). Caveolin scaffolding region and cholesterol-rich domains in membranes. J. Mol. Biol. 345, 339-350. doi: 10. 1016/j.jmb.2004.10.064

Eshraghi, A., Dixon, S. D., Tamilselvam, B., Kim, E. J., Gargi, A., Kulik, J. C., et al. (2014). Cytolethal distending toxins require components of the ER-associated degradation pathway for host cell entry. PLoS Pathog. 10:e1004295. doi: 10. 1371/journal.ppat.1004295

Eshraghi, A., Maldonado-Arocho, F. J., Gargi, A., Cardwell, M. M., Prouty, M. G., Blanke, S. R., et al. (2010). Cytolethal distending toxin family members are differentially affected by alterations in host glycans and membrane cholesterol. J. Biol. Chem. 285, 18199-18207. doi: 10.1074/jbc.M110.112912

Fahrer, J., Huelsenbeck, J., Jaurich, H., Dörsam, B., Frisan, T., Eich, M., et al. (2014). Cytolethal distending toxin (CDT) is a radiomimetic agent and induces persistent levels of DNA double-strand breaks in human fibroblasts. DNA Repair 18, 31-43. doi: 10.1016/j.dnarep.2014.03.002

Fernandez, K. R., Hansen, L. M., Vandamme, P., Beaman, B. L., and Solnick, J. (2002). Captive rhesus monkeys (Macaca mulatta) are commonly infected with Helicobacter cinaedi. J. Clin. Microbiol. 40, 1908-1912. doi: 10.1128/JCM.40.6. 1908-1912.2002

Figueiredo, R., Card, R., Nunes, C., AbuOun, M., Bagnall, M. C., Nunez, J., et al. (2015). Virulence characterization of Salmonella enterica by a New microarray: detection and evaluation of the cytolethal distending toxin gene activity in the unusual host S. Typhimurium. PLoS ONE 10:e0135010. doi: 10.1371/journal. pone. 0135010

Foster, G., Ross, H. M., Pennycott, T. W., Hopkins, G. F., and McLaren, I. M. (1998). Isolation of Escherichia coli O86:K61 producing cyto-lethal distending toxin from wild birds of the finch family. Lett. Appl. Microbiol. 26, 395-398. doi: 10.1046/j.1472-765X.1998.00359.x

Fouts, D. E., Mongodin, E. F., Mandrell, R. E., Miller, W. G., Rasko, D. A., Ravel, J., et al. (2005). Major structural differences and novel potential virulence mechanisms from the genomes of multiple Campylobacter species. PLoS Biol. 3:e15. doi: 10.1371/journal.pbio.0030015

Fox, J. (2007). Helicobacter bilis: bacterial provocateur orchestrates host immune responses to commensal flora in a model of inflammatory bowel disease. Gut 56, 898-900. doi: 10.1136/gut.2006.115428

Fox, J. G., Rogers, A. B., Whary, M. T., Ge, Z., Taylor, N. S., Xu, S., et al. (2004a). Gastroenteritis in NF-кB-deficient mice is produced with wild-type Camplyobacter jejuni but not with $C$. jejuni lacking cytolethal distending toxin despite persistent colonization with both strains. Infect. Immun. 72, 1116-1125. doi: 10.1128/IAI.72.2.1116-1125.2004

Fox, J. G., Ackerman, J. I., Taylor, N., Claps, M., and Murphy, J. C. (1987). Campylobacter jejuni infection in the ferret: an animal model of human capylobacteriosis. Am. J. Vet. Res. 48, 85-90.

Fox, J. G., Drolet, R., Higgins, R., Messier, S., Yan, L., Coleman, B. E., et al. (1996). Helicobacter canis isolated from a dog liver with multifocal necrotizing hepatitis. J. Clin. Microbiol. 34, 2479-2482.

Fox, J. G., Rogers, A. B., Whary, M. T., Taylor, N. S., Xu, S., Feng, Y., et al. (2004b). Helicobacter bilis-associated hepatitis in outbred mice. Comp. Med. 54, 571-577.

Frisan, T., Cortes-Bratti, X., and Thelestam, M. (2002). Cytolethal distending toxins and activation of DNA damage-dependent checkpoint responses. Int. J. Med. Microbiol. 291, 495-499. doi: 10.1078/1438-4221-00158

Frisan, T., Cortes-Bratti, X., Chaves-Olarte, E., Stenerlöw, B., and Thelastam, M. (2003). The Haemophilus ducreyi cytolethal distending toxin induces DNA double-strand breaks and promotes ATM-dependent activation of RhoA. Cell. Microbiol. 5, 695-707. doi: 10.1046/j.1462-5822.2003.00311.x

Frisk, A., Lebens, M., Johansson, C., Ahmed, H., Svensson, L., Ahlman, K., et al. (2001). The role of different protein components from the Haemophilus ducreyi cytolethal distending toxin in the generation of cell toxicity. Microb. Pathog. 30, 313-324. doi: 10.1006/mpat.2000.0436

Gardocki, M. E., Jani, N., and Lopes, J. M. (2005). Phosphatidylinositol biosynthesis: biochemistry and regulation. Biochim. Biophys. Acta 1735, 89-100. doi: 10.1016/j.bbalip.2005.05.006

Gargi, A., Reno, M., and Blanke, S. (2012). Bacterial toxin modulation of the eukaryotic cell cycle: are all cytolethal distending toxins created equally. Front. Cell. Infect. Microbiol. 2:124. doi: 10.3389/fcimb.2012.00124

Gargi, A., Tamilselvam, B., Powers, B., Prouty, M. G., Lincecum, T., Eshraghi, A., et al. (2013). Cellular interactions of the cytolethal distending toxins from Escherichia coli and Haemophilus ducreyi. J. Biol. Chem. 288, 7492-7505. doi: 10. 1074/jbc.M112.448118

Ge, Z., Feng, Y., Whary, M. T., Nambiar, P. R., Xu, S., Ng, V., et al. (2005). Cytolethal distending toxin is essential for Helicobacter hepaticus colonization in outbred Swiss Webster mice. Cell. Microbiol. 73, 201-206. doi: 10.1128/iai. 73.6.3559-3567.2005

Ge, Z., Robers, A. B., Feng, Y., Lee, A., Xu, S., Taylor, N. S., et al. (2007). Bacterial cytolethal distending toxin promotes the development of dysplasia in a model of microbially induced hepatocarcinogenesis. Cell. Microbiol. 9, 2070-2080. doi: 10.1111/j.1462-5822.2007.00939.x

Ge, Z., Schauer, D. B., and Fox, J. G. (2008). In vivo virulence properties of bacterial cytolethal-distending toxin. Cell. Microbiol. 10, 1599-1607. doi: 10.1111/j.14625822.2008.01173.x

Gebhart, C. J., Ward, G. E., Chang, K., and Kurtz, H. J. (1983). Campylobacter hyointestinalis (new species) isolated from swine with lesions of proliferative ileitis. Am. J. Vet. Res. 44, 361-367.

Gelfanova, V., Hansen, E. J., and Spinola, S. M. (1999). Cytolethal distending toxin of Haemophilus ducreyi induces apoptotic death of Jurkat T cells. Infect. Immun. 67, 6394-6402.

Graillot, V., Dormoy, I., Dupuy, J., Shay, J. W., Huc, L., Mirey, G., et al. (2016). Genotoxicity of Cytolethal Distending Toxin (CDT) on isogenic human colorectal cell lines: potential promoting effects for colorectal carcinogenesis. Front. Cell. Infect. Microbiol. 6:34. doi: 10.3389/fcimb.2016.00034

Grasso, F., and Frisan, T. (2015). Bacterial genotoxins: merging the DNA damage response into infection biology. Biomolecules 5, 1762-1782. doi: 10.3390/ biom5031762

Guerra, L., Buidi, R., Slot, I., Callegari, S., Sompallae, R., Pickett, C., et al. (2011a). Bacterial genotoxin triggers FEN1-dependent RhpA activation, cytoskeleton remodeling and cell survival. J. Cell Sci. 124, 2732-2742. doi: 10.1242/jcs. 085845

Guerra, L., Cortes-Bratti, X., Guidi, R., and Frisan, T. (2011b). The biology of the cytolethal distending toxins. Toxins 3, 172-190. doi: 10.3390/toxins30 30172

Guerra, L., Teter, K., Lilley, B. N., Stenerlöw, B., Holmes, R. K., Ploegh, H., et al. (2005). Cellular internalization of cytolethal distending toxin: a new end to a known pathway. Cell. Microbiol. 7, 921-934. doi: 10.1111/j.1462-5822.2005. 00520.x

Guha, M., and Mackman, N. (2002). The phosphatidylinositol 3-kinase-Akt pathway limits lipopolysaccharide activation of signaling pathways and expression of inflammatory mediators in human monocytic cells. J. Biol. Chem. 277, 32124-32132. doi: 10.1074/jbc.M203298200

Guidi, R., Guerra, L., Levi, L., Stenerlöw, B., Fox, J. G., Josenhans, C., et al. (2013). Chronic exposure to the cytolethal distending toxins of Gram-negative bacteria promotes genomic instability and altered DNA damage response. Cell. Microbiol. 15, 98-113. doi: 10.1111/cmi.12034

Haghjoo, E., and Galán, J. E. (2004). Salmonella typhi encodes a functional cytolethal distending toxin that is delivered into host cells by a bacterialinternalization pathway. Proc. Natl. Acad. Sci. U.S.A. 101, 4614-4619. doi: 10. 1073/pnas.0400932101

Hajishengallis, G., Darveau, R. P., and Curtis, M. A. (2012). The keystone-pathogen hypothesis. Nat. Rev. 10, 717-725. doi: 10.1038/nrmicro2873

Hassane, D. C., Lee, R. B., and Pickett, C. L. (2003). Campylobacter jejuni cytolethal distending toxin promotes DNA repair responses in normal human cells. Infect. Immun. 71, 541-545. doi: 10.1128/IAI.71.1.541-545.2003 
Hassane, D. C., Lee, R. B., Mendenhall, M. D., and Pickett, C. L. (2001). Cytolethal distending toxin demonstrates genotoxic activity in a yeast model. Infect. Immun. 69, 5752-5759. doi: 10.1128/IAI.69.9.5752-5759.2001

Hazeki, K., Nigorikawa, K., and Hazeki, O. (2007). Role of phosphoinositide 3kinase in innate immunity. Biol. Pharm. Bull. 30, 1617-1623. doi: 10.1248/bpb. 30.1617

Hickey, T. E., Majam, G., and Guerry, P. (2005). Intracellular survival of Campylobacter jejuni in human monocytic cells and induction of apoptotic death by cytholethal distending toxin. Infect. Immun. 73, 5194-5197. doi: 10. 1128/IAI.73.8.5194-5197.2005

Hinenoya, A., Naigita, A., Ninomiya, K., Asakura, M., Shima, K., Seto, K., et al. (2009). Prevalence and characteristics of cytolethal distending toxin-producing Escherichia coli from children with diarrhea in Japan. Microbiol. Immunol. 53, 206-215. doi: 10.1111/j.1348-0421.2009.00116.x

$\mathrm{Hu}, \mathrm{X}$., and Stebbins, C. E. (2006). Dynamics and assembly of the cytolethal distending toxin. Proteins 65, 843-855. doi: 10.1002/prot.21167

Huang, Y. H., and Sauer, K. (2010). Lipid signaling in T cell development and function. Cold Spring Harb. Perspect. Biol. 2, 1-25. doi: 10.1101/cshperspect. a002428

Hyma, K. E., Lacher, D. W., Nelson, A. M., Bumbaugh, A. C., Janda, J. M., Strockbine, N. A., et al. (2005). Evolutionary genetics of a new pathogenic Escherichia species: Escherichia albertii and related Shigella boydii strains. J. Bacteriol. 187, 619-628. doi: 10.1128/JB.187.2.619-628.2005

Jafurulla, M., Tiwari, S., and Chattopadhyay, A. (2011). Identification of cholesterol recognition amino acid consensus (CRAC) motif in G-protein coupled receptors. Biochem. Biophys. Res. Commun. 404, 569-573. doi: 10.1016/j.bbrc. 2010.12.031

Jain, D., Prasad, K. N., Sinha, S., and Husain, N. (2008). Differences in virulence attributes between cytolethal distending toxin positive and negative Campylobacter jejuni strains. J. Med. Microbiol. 57, 267-272. doi: 10.1099/jmm. 0.47317-0

Jain, D., Prasad, K. N., Sinha, S., and Vishwakarma, A. L. (2009). Cell cycle arrest \& apoptosis of epithelial cell line by cytolethal distending toxin positive Campylobacter jejuni. Indian J. Med. Res. 129, 418-423.

Jamin, N., Neumann, J. M., Ostuni, M. A., Vu, T. K., Yao, Z. X., Murail, S., et al. (2005). Characterization of the cholesterol recognition aminio acid consensus sequence of the peripheral-type benzodiazepine receptor. Mol. Endocrinol. 19, 588-594. doi: 10.1210/me.2004-0308

Janka, A., Bielaszewska, M., Dobrindt, U., Greune, L., Schmidt, M. A., and Karch, H. (2003). Cytolethal distending toxin gene cluster in enterohemorrhagic Escherichia coli $\mathrm{O} 157: \mathrm{H}^{-}$and O157:H7: characterization and evolutionary considerations. Infect. Immun. 71, 3634-3638. doi: 10.1128/IAI.71.6.3634-36 38.2003

Jinadasa, R. N., Bloom, S. E., Weiss, R. S., and Duhamel, G. E. (2011). Cytolethal distending toxin: a conserved bacterial genotoxin that blocks cell cycle progression, leading to apoptosis of a broad range of mammalian cell lineages. Microbiology 157, 1851-1875. doi: 10.1099/mic.0.049536-0

Johnson, T. J., DebRoy, C., Belton, S., Williams, M., Lawrence, M. L., Nolan, L. K., et al. (2010). Pyrosequencing of the Vir plasmid of necrotoxigenic Escherichia coli. Vet. Microbiol. 144, 100-109. doi: 10.1016/j.vetmic.2009.12.022

Johnson, T., Kariyawasam, S., Wannemuehler, Y., Mangiamele, P., Johnson, S., Doetkott, C., et al. (2007). The genome sequence of avian pathogenic Escherichia coli strain 01:K1:H7 shares strong similarities with human extraintestinal pathogenic E. coli genomes. J. Bacteriol. 189, 3228-3236. doi: 10. 1128/JB.01726-06

Johnson, W. M., and Lior, H. (1988a). A new heat-labile cytolethal distending toxin (CLDT) produced by Campylobacter spp. Microb. Pathog. 4, 115-126. doi: 10. 1016/0882-4010(88)90053-8

Johnson, W. M., and Lior, H. (1988b). A new heat-labile cytolethal distending toxin (CLDT) produced by Escherichia coli isolates from clinical material. Microb. Pathog. 4, 103-113. doi: 10.1016/0882-4010(88)90052-6

Johnson, W., and Lior, H. (1987). Production of Shiga toxin and a cytolethal distending toxin (CLDT) by serogroups of Shigella spp. FEMS Microbiol. Lett. 48, 235-238. doi: 10.1111/j.1574-6968.1987.tb02548.x

Kamei, K., Asakura, M., Somroop, S., Hatanaka, N., Hinenoya, A., Nagita, A., et al. (2014). A PCR-RFLP assay for the detection and differentiation of Campylobacter jejuni, C. coli, C. fetus, C. hyointestinalis, C. lari, C. helveticus and C. upsaliensis. J. Med. Microbiol. 63, 659-666. doi: 10.1099/jmm.0.07 1498-0

Kang, P., Korostoff, J., Volgina, A., Grzesik, W., and DiRienzo, J. M. (2005). Differential effect of the cytolethal distending toxin of Actinobacillus actinomycetemcomitans on co-cultures of human oral cells. J. Med. Microbiol. 54, 785-794. doi: 10.1099/jmm.0.46077-0

Kanno, F., Korostoff, J., Volgina, A., and DiRienzo, J. M. (2005). Resistance of human periodontal ligament fibroblasts to the cytolethal distending toxin of Actinobacillus actinomycetemcomitans. J. Periodontol. 76, 1189-1201. doi: 10. 1902/jop.2005.76.7.1189

Kostia, S., Veijalainen, P., Hirvi, U., and Hänninen, M. L. (2003). Cytolethal distending toxin $\mathrm{B}$ gene ( $\mathrm{cdtB}$ ) homologues in taxa 2, 3 and 8 and in six canine isolates of Helicobacter sp. flexispira. J. Med. Microbiol. 52, 103-108. doi: 10. 1099/jmm.0.04920-0

Kraub, M., and Haucke, V. (2007). Phosphoinositides: regulators of membrane traffic and protein function. FEBS Lett. 581, 2105-2111. doi: 10.1016/j.febslet. 2007.01.089

Krystal, G. (2000). Lipid phosphatases in the immune system. Semin. Immunol. 12, 397-403. doi: 10.1006/smim.2000.0222

Lagergård, T. (1992). The role of Haemophilus ducreyi bacteria, cytotoxin, endotoxin and antibodies in animal models for study of chancroid. Microb. Pathog. 13, 203-217. doi: 10.1016/0882-4010(92)90021-F

Lagergård, T., and Purven, M. (1993). Neutralizing antibodies to Haemophilus ducreyi cytotoxin. Infect. Immun. 61, 1589-1592.

Lai, C.-K., Chen, Y.-A., Lin, C.-J., Lin, H.-J., Kao, M.-C., Huang, M.-Z., et al. (2016). Molecular mechanisms and potential clinical applications of campylobacter jejuni cytolethal distending toxin. Front. Cell. Infect. Microbiol. 6:9. doi: 10. 3389/fcimb.2016.00009

Lai, C. H., Lai, C. K., Lin, Y. J., Hung, C. L., Chu, C. H., Feng, C. L., et al. (2013). Characterization of putative cholesterol recognition/interaction amino acid consensus-like motif of Campylobacter jejuni cytolethal distending toxin C. PLoS ONE 8:e66202. doi: 10.1371/journal.pone.0066202

Lai, C. K., Su, J. C., Lin, Y. H., Chang, C. S., Feng, C. L., Lin, H. J., et al. (2015). Involvement of cholesterol in Campylobacter jejuni cytolethal distending toxin-induced pathogenesis. Future Microbiol. 10, 489-501. doi: 10.2217/fmb. 14.119

Lara-Tejero, M., and Galán, J. E. (2000). A bacterial toxin that controls cell cycle progression as a deoxyribonuclease I-like protein. Science 290, 354-357. doi: 10. $1126 /$ science. 290.5490 .354

Lara-Tejero, M., and Galán, J. E. (2001). CdtA, CdtB, and CdtC form a tripartite complex that is required for cytolethal distending toxin activity. Infect. Immun. 69, 4358-4365. doi: 10.1128/IAI.69.7.4358-4365.2001

Lecanu, L., Yao, Z., McCourty, A., Sidahmed, E., Orellana, M., Burnier, M., et al. (2013). Control of hypercholesterolemia and atherosclerosis using the cholesterol recognition/interaction amino acid sequence of the translocator protein TSPO. Steroids 78, 137-146. doi: 10.1016/j.steroids.2012. 10.018

Lee, C.-H., Inoki, K., and Guan, K.-L. (2007). mTOR pathway as a target in tissue hypertrophy. Annu. Rev. Pharmacol. Toxicol. 47, 443-467. doi: 10.1146/ annurev.pharmtox.47.120505.105359

Leemann, C., Gambillara, E., Prod'hom, G., Jaton, K., Panizon, R., Bille, J., et al. (2006). First case of bacteremia and multifocal cellulitis due to Helicobacter canis in an immunocompetent patient. J. Clin. Microbiol. 44, 4598-4600. doi: 10.1128/JCM.01453-06

Lewis, D. A., Stevens, M. K., Latimer, J. L., Ward, C. K., Deng, K., Blick, R., et al. (2001). Characterization of Haemophilus ducreyi cdtA, cdtB, and cdtC mutants in in vitro and in vivo systems. Infect. Immun. 69, 5626-5634. doi: 10.1128/IAI. 69.9.5626-5634.2001

Lewis, D., and Mitja, O. (2016). Haemophilus ducreyi: from sexually transmitted infection to skin ulcer pathogen. Curr. Opin. Infect. Dis. 29, 52-57. doi: 10.1097/ QCO.0000000000000226

Li, H., and Papadopoulos, V. (1998). Peripheral-type benzodiazepine receptor function in cholesterol transport. Identification of a putative cholesterol recognition/interaction amino acid sequence and consensus pattern. Endocrinology 139, 4991-4997. doi: 10.1210/en.139.12.4991

Li, L., Sharipo, A., Chaves-Olarte, E., Mascucci, M., Levitsky, V., Thelastam, M., et al. (2002). The Haemophilus ducreyi cytolethal distending toxin activates 
sensors of DNA damage and repair compelxes in proliferating and nonproliferating cells. Cell. Microbiol. 4, 87-99. doi: 10.1046/j.1462-5822.2002. 00174.x

Liu, Y., Li, Y., and Lu, X. (2016). Regulators in the DNA damage response. Arch. Biochem. Biophys. 594, 18-25. doi: 10.1016/j.abb.2016.02.018

Liyanage, N. P., Dassanayake, R. P., Kuszynski, C. A., and Duhamel, G. E. (2013). Contribution of Helicobacter hepaticus cytolethal distending toxin subunits to human epithelial cell cycle arrest and apoptotic death in vitro. Helicobacter 18, 433-443. doi: 10.1111/hel.12084

Liyanage, N. P., Manthey, K. C., Dassanayake, R. P., Kuszynski, C. A., Oakley, G. G., and Duhamel, G. E. (2010). Helicobacter hepaticus cytolethal distending toxin causes cell death in intestinal epithelial cells via mitochondrial apoptotic pathway. Helicobacter 15, 98-107. doi: 10.1111/j.1523-5378.2010.00749.x

Lundqvist, A., Fernandez-Rodrigues, J., Ahlman, K., and Lagergård, T. (2010). Detoxified Haemophilus ducreyi cytolethal distending toxin and induction of toxin specific antibodies in the genital tract. Vaccine 28, 5768-5773. doi: 10. 1016/j.vaccine.2010.06.032

Luo, J. (2009). Glycogen synthase kinase $3 \beta$ (GSK3 $\beta$ ) in tumorigenesis and cancer chemotherapy. Cancer Lett. 273, 194-200. doi: 10.1016/j.canlet.2008.05.045

Mao, X., and DiRienzo, J. M. (2002). Functional studies of the recombinant subunits of a cytolethal distending toxin. Cell. Microbiol. 4, 245-255. doi: 10. 1046/j.1462-5822.2002.00186.x

March, M., and Ravichandran, K. (2002). Regulation of the immune response by SHIP. Semin. Immunol. 14, 37-47. doi: 10.1006/smim.2001.0340

Matangkasombut, O., Wattanawaraporn, R., Tsuruda, K., Ohara, M., Sugai, M., and Mongkolsuk, S. (2010). Cytolethal distending toxin from Aggregatibacter actinomycetemcomitans induces DNA damage, S/G2 cell cycle arrest and caspase-independent death in a Saccharomyces cerevisiae model. Infect. Immun. 78, 783-792. doi: 10.1128/IAI.00857-09

Matsuo, Y., Yamada, A., Tsukamoto, K., Tamura, H., Ikezawa, H., Nakamura, H., et al. (1996). A distant evolutionary relationship between bacterial sphingomyelinase and mammalian DNase I. Protein Sci. 5, 2459-2467. doi: 10. 1002/pro.5560051208

Mayer, M. P., Bueno, L. C., Hansen, E. J., and DiRienzo, J. M. (1999). Identification of a cytolethal distending toxin gene locus and features of a virulence-associated region in Actinobacillus actinomycetemcomitans. Infect. Immun. 67, 1227-1237.

McSweeney, L. A., and Dreyfus, L. A. (2004). Nuclear localization of the Escherichia coli cytolethal distending toxin CdtB subunit. Cell. Microbiol. 6, 447-458. doi: $10.1111 / j .1462-5822.2004 .00373 . x$

McSweeney, L. A., and Dreyfus, L. A. (2005). Carbohydrate-binding specificity of the Escherichia coli cytolethal distending toxin CdtA-II and CdtC-II subunits. Infect. Immun. 73, 2051-2060. doi: 10.1128/IAI.73.4.2051-2060.2005

Melito, P. L., Munro, C., Chipman, P. R., Woodward, D. L., Booth, T. F., and Rodgers, F. G. (2001). Helicobacter winghamensis sp. nov, a novel Helicobacter sp. isolated from patients with gastroenteritis. J. Clin. Microbiol. 39, 2412-2417. doi: 10.1128/JCM.39.7.2412-2417.2001

Mezal, E. H., Bae, D., and Khan, A. A. (2014). Detection and functionality of the CdtB, PltA, and PltB from Salmonella enterica serovar Javiana. Pathog. Dis. 72, 95-103. doi: 10.1111/2049-632X.12191

Mise, K., Akifusa, S., Watarai, S., Ansai, T., Nishihara, T., and Takehara, T. (2005). Involvement of ganglioside GM3 in G2/M cell cycle arrest of human monocytic cells induced by Actinobacillus actinomycetemcomitans cytolethal distending toxin. Infect. Immun. 73, 4846-4852. doi: 10.1128/IAI.73.8.48464852.2005

Mizuno, K., Takama, K., and Suzuki, S. (1994). Characteristics of cytotoxin produced by Campylobacter jejuni strains. Microbios 78, 215-228.

Mogi, M. (2004). Differential expression of RANKL and osteoprotgerin in gingival crevicular fluid of patients with periodontitis. J. Dent. Res. 83, 166-169. doi: 10. $1177 / 154405910408300216$

Molnarfi, N., Gruaz, L., Dayer, J., and Burger, D. (2007). Opposite regulation of ILlïĄć and secreted IL-1 receptor antagonist production by phophatidylinositidekinases in human monocytes activated by lipopolysaccharides or contact with T cells. J. Immunol. 178, 446-454. doi: 10.4049/jimmunol.178.1.446

Moolhuijzen, P. M., Lew-Tabor, A. E., Wlodek, B. M., Aguero, F. G., Comerci, D. J., Ugalde, R. A., et al. (2009). Genomic analysis of Campylobacter fetus subspecies: identification of candidate virulence determinants and diagnostic assay targets. BMC Microbiol. 9:86. doi: 10.1186/1471-2180-9-86
Mooney, A., Clyne, M., Curran, T., Doherty, D., Kilmartin, B., and Bourke, B. (2001). Campylobacter upsaliensis exerts a cytolethal distending toxin effect on HeLa cells and T lymphocytes. Microbiology 147, 735-743. doi: 10.1099/ 00221287-147-3-735

Nalbant, A., Chen, C., Wang, Y., and Zadeh, H. H. (2003). Induction of Tcell apoptosis by Actinobacillus actinomycetemcomitans mutants with deletion of ltxA and $c d t A B C$ genes: possible activity of GroEL-like molecule. Oral Microbiol. Immunol. 18, 339-349. doi: 10.1046/j.0902-0055.2003.00082.x

Nesic, D., Hsu, Y., and Stebbins, C. E. (2004). Assembly and function of a bacterial genotoxin. Nature 429, 429-433. doi: 10.1038/nature02532

Nishikubo, S., Ohara, M., Ueno, Y., Ikura, M., Kurihara, H., Komatsuzawa, H., et al. (2003). An N-terminal segment of the active component of the bacterial genotoxin cytolethal distending toxin B (CDTB) directs CDTB into the nucleus. J. Biol. Chem. 278, 50671-50681. doi: 10.1074/jbc.M305062200

Oaks, J. L., Besser, T. E., Walk, S. T., Gordon, D. M., Beckmen, K. B., Burek, K. A., et al. (2010). Escherichia albertii in wild and domestic birds. Emerg. Infect. Dis. 16, 638-646. doi: 10.3201/eid1604.090695

Oddi, S., Dainese, E., Fezza, F., Lanuti, M., Barcaroli, D., DeLaurenzi, V., et al. (2011). Functional characterization of putative cholesterol binding sequence (CRAC) in human type-1 cannabinoid receptor. J. Neurochem. 116, 858-865. doi: 10.1111/j.1471-4159.2010.07041.x

Ohara, M., Hayashi, T., Kusonoki, Y., Miyauchi, M., Takata, T., and Sugai, M. (2004). Caspase- 2 and caspase-7 are involved in cytolethal distending toxininduced apoptosis in Jurkat and MOLT-4 T-cell lines. Infect. Immun. 72, 871-879. doi: 10.1128/IAI.72.2.871-879.2004

Ohara, M., Hayashi, T., Kusunoki, Y., Nakachi, K., Fujiwara, T., Komatsuzawa, H., et al. (2008). Cytolethal distending toxin induces caspase-dependent and independent cell death in MOLT-4 cells. Infect. Immun. 76, 4783-4791. doi: 10. 1128/IAI.01612-07

Ohara, M., Miyauchi, M., Tsuruda, K., Takata, T., and Sugai, M. (2011). Topical application of Aggregatibacter actinomycetemcomitans cytolethal distending toxin induces cell cycle arrest in the rat gingival epithelium in vivo. J. Periodontal Res. 46, 389-395. doi: 10.1111/j.1600-0765.2011.01348.x

Ohguchi, M., Ishisaki, A., Okahashi, N., Koide, M., Koseki, T., Yamato, K., et al. (1998). Actinobacillus actinomycetemcomitans toxin induces both cell cycle arrest in the G2/M phase and apoptosis. Infect. Immun. 66, 5980-5987.

Ohya, T., Tominaga, K., and Nakazawa, M. (1993). Production of cytolethal distending toxin (CLDT) by Campylobacter fetus subsp. fetus isolated from calves. J. Vet. Med. Sci. 55, 507-509. doi: 10.1292/jvms.55.507

Okeke, I. N., Lamikanra, A., Steinrück, H., and Kaper, J. B. (2000). Characterization of Escherichia coli strains from cases of childhood diarrhea in provincial southwestern Nigeria. J. Clin. Microbiol. 38, 7-12.

Okuda, J., Fukumoto, M., Takeda, Y., and Nishibuchi, M. (1997). Examination of diarrheagenicity of cytolethal distending toxin: suckling mouse response to the products of the cdtABC genes of Shigella dysenteriae. Infect. Immun. 65, $428-433$.

Okuda, J., Kurazono, H., and Takeda, Y. (1995). Distribution of the cytolethal distending toxin A gene (cdtA) among species of Shigella and Vibrio, and cloning and sequencing of the cdt gene from Shigella dysenteriae. Microb. Pathog. 18, 167-172. doi: 10.1016/S0882-4010(95)90022-5

Parkhill, J., Dougan, G., James, K., Thomson, N., Pickard, D., Wain, J., et al. (2001). Complete genome sequence of a multiple drug resistant Salmonella enterica serovar Typhi CT18. Nature 413, 848-852. doi: 10.1038/35101607

Pérès, S. Y., Marchès, O., Daigle, F., Nougayrede, J. P., Herault, F., Tasca, C., et al. (1997). A new cytolethal distending toxin (CDT) from Escherichia coli CNF2 blocks HeLa cell division in G2/M phase. Mol. Microbiol. 24, 1095-1107. doi: 10.1046/j.1365-2958.1997.4181785.x

Péré-Védrenne, C., Cardinaud, B., Varon, C., Mocan, I., Buissonniere, A., Izotte, J., et al. (2016). The cytolethal distending toxin subunit CdtB of helicobacter induces a Th17-related and antimicrobial signature in intestinal and hepatic cells in vitro. J. Infect. Dis. 213, 1979-1989. doi: 10.1093/infdis/ jiw042

Pickett, C. L., and Whitehouse, C. A. (1999). The cytolethal distending toxin family. Trends Microbiol. 7, 292-297. doi: 10.1016/S0966-842X(99)01537-1

Pickett, C. L., Cottle, D. L., Pesci, E. C., and Bikah, G. (1994). Cloning, sequencing, and expression of the Escherichia coli cytolethal distending toxin genes. Infect. Immun. 62, 1046-1051. 
Pickett, C. L., Lee, R. B., Eyigor, A., Elitzur, B., Fox, E. M., and Strockbine, N. A. (2004). Patterns of variations in Escherichia coli strains that produce cytolethal distending toxin. Infect. Immun. 72, 684-690. doi: 10.1128/IAI.72.2.684-690. 2004

Pickett, C. L., Pesci, E. C., Cottle, D. L., Russell, G., Erdem, A. N., and Zeytin, H. (1996). Prevalence of cytolethal distending toxin production in Campylobacter jejuni and relatedness of Campylobacter sp. cdtB gene. Infect. Immun. 64, 2070-2078.

Pratt, J. S., Sachen, K. L., Wood, H. D., Eaton, K. A., and Young, V. B. (2006). Modulation of host immune responses by the cytolethal distending toxin of Helicobacter hepaticus. Infect. Immun. 74, 4496-4504. doi: 10.1128/IAI.00503-06

Purdy, D., Buswell, C. M., Hodgson, A. E., McAlpine, K., Henderson, I., and Leach, S. A. (2000). Characterisation of cytolethal distending toxin (CDT) mutants of Campylobacter jejuni. J. Med. Microbiol. 49, 473-479. doi: 10.1099/0022-131749-5-473

Purvén, M., and Lagergård, T. (1992). Haemophilus ducreyi, a cytotoxin-producing bacterium. Infect. Immun. 60, 1156-1162.

Purvén, M., Falsen, E., and Lagergård, T. (1995). Cytotoxin production in 100 strains of Haemophilus ducreyi from different geographic locations. FEMS Microbiol. Lett. 129, 221-224. doi: 10.1016/0378-1097(95)00161-W

Rabin, S., Flitton, J., and Demuth, D. R. (2009). Aggregatibacter actinomycetemcomitans cytolethal distending toxin induces aoptosis in nonproliferating macrophages by a phosphatase-independent mechanism. Infect. Immun. 77, 3161-3169. doi: 10.1128/IAI.01227-08

Rayasam, G., Tulasi, V., Sokhi, R., Davis, J., and Ray, A. (2009). Glycogen synthase kinase 3: more than a namesake. Br. J. Pharmacol. 156, 885-898. doi: 10.1111/j. 1476-5381.2008.00085.x

Sahin, O., Plummer, P., Jordan, D., Sulaj, K., Pereira, S., Robbe-Austerman, S., et al. (2008). Emergence of a tetracycline-resistant Campylobacter jejuni clone associated with outbreaks of ovine abortionin the United States. J. Clin. Microbiol. 46, 1663-1671. doi: 10.1128/JCM.00031-08

Sasaki, T., Sasaki, J., Sakai, T., Takasuga, S., and Suzuki, A. (2007). The physiology of phosphoinositides. Biol. Pharm. Bull 30, 1599-1604. doi: 10.1248/bpb.30.1599

Sato, T., Koseki, T., Yamato, K., Saiki, K., Konishi, K., Yoshikawa, M., et al. (2002). p53-independent expression of p21(CIP1/WAF1) in plasmacytic cells during G(2) cell cycle arrest induced by Actinobacillus actinomycetemcomitans cytolethal distending toxin. Infect. Immun. 70, 528-534. doi: 10.1128/IAI.70.2. 528-534.2002

Schulze, F., Hanel, I., and Börrmann, E. (1998). Formation of cytotoxins by enteric Campylobacter in humans and animals. Zentralbl. Bakteriol. 288, 225-236. doi: 10.1016/S0934-8840(98)80045-5

Scott, D. A., and Kaper, J. B. (1994). Cloning and sequencing of the genes encoding Escherichia coli cytolethal distending toxin. Infect. Immun. 62, 244-251.

Seminario, M., and Wange, R. (2003). Lipid phosphatases in the regulation of T cell activation: living up to their PTEN-tial. Immunol. Rev. 192, 80-97. doi: 10. 1034/j.1600-065X.2003.00013.X

Sert, V., Cans, C., Tasca, C., Bret-Bennis, L., Oswald, E., Ducommun, B., et al. (1999). The bacterial cytolethal distending toxin (CDT) triggers a G2 cell cycle checkpoint in mammalian cells without preliminary induction of DNA strand breaks. Oncogene 18, 6296-6304. doi: 10.1038/sj.onc.1203007

Shen, Z., Feng, Y., Rogers, A., Rickman, B., Whary, M., Xu, S., et al. (2009). Cytolethal distending toxin promotes Helicobacter cinaedi-associated typhlocolitis in interleukin-10-deficient mice. Infect. Immun. 77, 2508-2516. doi: 10.1128/IAI.00166-09

Shen, Z., Xu, S., Dewhirst, F. E., Paster, B. J., Pena, J. A., Modlin, I. M., et al. (2005). A novel enterohepatic Helicobacter species 'Helicobacter mastomyrinus' isolated from the liver and intestine of rodents. Helicobacter 10, 59-70. doi: 10. 1111/j.1523-5378.2005.00292.x

Shenker, B. J., Besack, D., McKay, T. L., Pankoski, L., Zekavat, A., and Demuth, D. R. (2004). Actinobacillus actinomycetemcomitans cytolethal distending toxin (Cdt): evidence that teh holotoxin is composed of three subunits: CdtA, CdtB, and CdtC. J. Immunol. 172, 410-417. doi: 10.4049/jimmunol.172.1.410

Shenker, B. J., Boesze-Battaglia, K., Scuron, M. D., Walker, L. P., Zekavat, A., and Dlakic, M. (2016a). The toxicity of the Aggregatibacter actinomycetemcomitans cytolethal distending toxin correlates with its phosphatidylinositol-3,4,5-triphosphate phosphatase activity. Cell. Microbiol. 18, 223-243. doi: 10.1111/cmi.12497

Shenker, B. J., Dlakic, M., Walker, L., Besack, D., Jaffe, E., Labelle, E., et al. (2007). A novel mode of action for a microbial-derived immunotoxin: the cytolethal distending toxin subunit B exhibits phosphatidylinositol $(3,4,5)$ tri-phosphate phospatase activity. J. Immunol. 178, 5099-5108. doi: 10.4049/jimmunol.178. 8.5099

Shenker, B. J., Hoffmaster, R. H., McKay, T. L., and Demuth, D. R. (2000). Expression of the cytolethal distending toxin (Cdt) operon in Actinobacillus actinoimycetemcomitans: evidence that the CdtB protein is responsible for G2 arrest of the cell cyclein human T-cells. J. Immunol. 165, 2612-2618. doi: 10. 4049/jimmunol.165.5.2612

Shenker, B. J., Hoffmaster, R. H., Zekavat, A., Yamguchi, N., Lally, E. T., and Demuth, D. R. (2001). Induction of apoptosis in human T cells by Actinobacillus actinomycetemcomitans cytolethal distending toxin is a consequence of G2 arrest of the cell cycle. J. Immunol. 167, 435-441. doi: 10. 4049/jimmunol.167.1.435

Shenker, B. J., McKay, T. L., Datar, S., Miller, M., Chowhan, R., and Demuth, D. R. (1999). Actinobacillus actinomycetemcomitans immunosuppressive protein is a member of the family of cytolethal distending toxins capable of causing a G2 arrest in human T cells. J. Immunol. 162, 4773-4780.

Shenker, B. J., Ojcius, D. M., Walker, L. P., Zekavat, A., Scuron, M. D., and Boesze-Battaglia, K. (2015). Aggregatibacter actinomycetemcomitans cytolethal distending toxin activates the NLRP3 inflammasome in human macrophages, leading to the release of proinflammatory cytokines. Infect. Immun. 83, 1487-1496. doi: 10.1128/IAI.03132-14

Shenker, B. J., Boesze-Battaglia, K., Zekavat, A., Walker, L., Besack, D., and Ali, H. (2010). Inhibition of mast cell degranulation by a chimeric toxin containing a novel phosphatidylinositol-3,4,5-triphosphate phosphatase. Mol. Immunol. 48, 203-210. doi: 10.1016/j.molimm.2010.08.009

Shenker, B. J., Walker, L. P., Zekavat, A., and Boesze-Battaglia, K. (2016b). Lymphoid susceptibility to the Aggregatibacter actinomycetemcomitans cytolethal distending toxin is dependent upon baseline levels of the signaling phosphatidylinositol-3,4,5-triphosphate. Mol. Oral Microbiol. 31, 33-42. doi: $10.1111 /$ omi.12127

Shenker, B. J., Walker, L., Zekavat, A., Dlakic, M., and Boesze-Battaglia, K. (2014). Blockade of the PI-3K signaling pathway by the Aggregatibacter actinomycetemcomitans cyotolethal distending toxin induces macrophages to synthesize and secrete pro-inflammatory cytokines. Cell. Microbiol. 16, 1391-1404. doi: 10.1111/cmi.12299

Shigematsu, M., Harada, Y., Sekizuka, T., Murayama, O., Takamiya, S., Millar B. C., et al. (2006). Genetic heterogeneity of the cytolethal distending toxin B (cdtB) gene locus among isolates of Campylobacter lari. Br. J. Biomed. Sci. 63, 179-181.

Shima, A., Hinenoya, A., Asakura, M., Sugimoto, N., Tsukamoto, T., Ito, H., et al. (2012). Molecular characterizations of cytolethal distending toxin produced by Providencia alcalifaciens strains isolated from patients with diarrhea. Infect. Immun. 80, 1323-1332. doi: 10.1128/IAI.05831-11

Singh, A., McMillan, J., Bukiya, A., Burton, B., Parrill, A., and Dopico, A. (2012). Multiple cholesterol recognition/interaction amino acid consensus (CRAC) motifs in cytosolic C tail of Slol subunit determine cholesterol sensitivity of $\mathrm{Ca}^{2+}$ - and voltage-gated $\mathrm{K}^{+}$(BK) channels. J. Biol. Chem. 287, 20509-20521. doi: 10.1074/jbc.M112.356261

Skyberg, J. A., Logue, C. M., and Nolan, L. K. (2006). Virulence genotyping of Salmonella spp. with multiplex PCR. Avian Dis. 50, 77-81. doi: 10.1637/7417.1

Smith, J. L., and Bayles, D. O. (2006). The contribution of cytolethal distending toxin to bacterial pathogenesis. Crit. Rev. Microbiol. 32, 227-248. doi: 10.1080/ 10408410601023557

Song, J., Gao, X., and Galán, J. (2013). Structure and function of the Salmonella Typhi chimaeric A(2)B(5) typhoid toxin. Nature 499, 350-354. doi: 10.1038/ nature 12377

Sreenivasan, P. K., LeBlanc, D. J., Lee, L. N., and Fives-Taylor, P. (1991). Transformation of Actinobacillus actinomycetemcomitans by electroporation, utilizing constructed shuttle plasmids. Infect. Immun. 59, 4621-4627.

Stevens, M., Latimer, J., Lumbley, S., Ward, C. K., Cope, L., Lagergard, T., et al. (1999). Characterization of a Haemophilus ducreyi mutant deficient in expression of cytolethal distending toxin. Infect. Immun. 67, 3900-3908. 
Strahl, T., and Thorner, J. (2007). Synthesis and function of membrane phosphoinositides in budding yeast, Saccharomyces cerevisiae. Biochim. Biophys. Acta 1771, 353-404. doi: 10.1016/j.bbalip.2007.01.015

Suez, J., Porwollik, S., Dagan, A., Marzel, A., Schorr, Y., Desai, P., et al. (2013). Virulence gene profiling and pathogenicity characterization of non-typhoidal Salmonella accounted for invasive disease in humans. PLoS ONE 8:e58449. doi: 10.1371/journal.pone.0058449

Sugai, M., Kawamoto, T., Peres, S., Ueno, Y., Komatsuzawa, H., Fujiwara, T., et al. (1998). The cell cycle-specific growth-inhibitory factor produced by Actinobacillus actinomycetemcomitans is a cytolethal distending toxin. Infect. Immun. 66, 5008-5019.

Svab, D., Horvath, B., Maroti, G., Dobrindt, U., and Toth, I. (2013). Sequence variability of $\mathrm{P} 2$-like prophage genomes carrying the cytolethal distending toxin V operon in Escherichia coli O157. Appl. Environ. Microbiol. 79, 4958-4964. doi: 10.1128/AEM.01134-13

Svensson, L. A., Tarkowski, A., Thelestam, M., and Lagergard, T. (2001). The impact of Haemophilus ducreyi cytolethal distending toxin on cells involved in immune response. Microb. Pathog. 30, 157-166. doi: 10.1006/mpat.200 0.0422

Taieb, F., Petit, C., Nougayrede, J.-P., and Oswald, E. (2016). The Enterobacterial genotoxins: cytolethal distending toxin and colibactin. EcoSal Plus 7. doi: 10. 1128/ecosalplus.ESP-0008-2016

Taieb, F., Svab, D., Watrin, C., Oswald, E., and Toth, I. (2015). Cytolethal distending toxin $\mathrm{A}, \mathrm{B}$ and $\mathrm{C}$ subunit proteins are necessary for the genotoxic effect of Escherichia coli CDT-V. Acta Vet. Hung. 63, 1-10. doi: 10.1556/AVet. 2015.001

Tauxe, R. (1997). Emerging foodborne diseases: an evolving public health challenge. Emer. Infect. Dis. 3, 425-434. doi: 10.3201/eid0304.970403

Taylor, N. S., Ge, Z., Shen, Z., Dewhirst, F. E., and Fox, J. G. (2003). Cytolethal distending toxin: a potential virulence factor for Helicobacter cinaedi. J. Infect. Dis. 188, 1892-1897. doi: 10.1086/379837

Thelastam, M., and Frisan, T. (2004). Cytolethal distending toxins. Rev. Physiol. Biochem. Pharmacol. 152, 111-133. doi: 10.1007/s10254-004$0030-8$

Toth, I., Herault, F., Beutin, L., and Oswald, E. (2003). Production of cytolethal distending toxins by pathogenic Escherichia coli strains isolated from human and animal sources: establishment of the existence of a new cdt variant (Type IV). J. Clin. Microbiol. 41, 4285-4291. doi: 10.1128/JCM.41.9.4285-429 1.2003

Toth, I., Nougayrede, J. P., Dobrindt, U., Ledger, T. N., Boury, M., Morabito, S., et al. (2009). Cytolethal distending toxin type I and type IV genes are framed with lambdoid prophage genes in extraintestinal pathogenic Escherichia coli. Infect. Immun. 77, 492-500. doi: 10.1128/IAI.00962-08

Tsujishita, Y., Guo, S., Stolz, L., York, J., and Hurley, H. (2001). Specificity determinants in phosphoinosite dephosphorylation: crystal structure of an archetypal inositol polyphosphate 5-phosphatase. Cell 105, 379-389. doi: 10. 1016/S0092-8674(01)00326-9

Varon, C., Mocan, I., Mihi, B., Pere-Vedrenne, C., Aboubacar, A., Morate, C., et al. (2014). Helicobacter pullorum cytolethal distending toxin targets vinculin and cortactin and triggers formation of lamellipodia in intestinal epithelial cells. $J$. Infect. Dis. 209, 588-599. doi: 10.1093/infdis/jit539

Vincent, N., Genin, C., and Malvoisin, E. (2002). Identification of a conserved domain of the HIV-1 transmembrane protein gp41 which interacts with cholesteryl groups. Biochim. Biophys. Acta 1567, 157-164. doi: 10.1016/S00052736(02)00611-9

Wang, H., Li, Q., Bai, X., Xu, Y., Zhao, A., Sun, H., et al. (2016). Prevalence of eae-positive, lactose non-fermenting Escherichia albertii from retail raw meat in China. Epidemiol. Infect. 144, 45-52. doi: 10.1017/S0950268815001120

Whitehouse, C. A., Balbo, P., Peter, M. E., Cottle, D. L., Mirabito, P., and Pickett, C. L. (1998). Campylobacter jejuni cytolethal distending toxin causes a G2 phase cell cycle block. Infect. Immun. 66, 208-212.

Wising, C., Svensson, L., Aitken, A., Sundaeus, V., Ahlman, K., Jonsson, I., et al. (2002). Toxicity and immunogenicity of purified Haemophilus ducreyi cytolethal distending toxin in a rabbit model. Microb. Pathog. 33, 49-62. doi: 10. 1006/mpat.2002.0516

Xu, T., Lundqvist, A., Ahmed, H. J., Eriksson, K., Yang, Y., and Lagergard, T. (2004). Interactions of Haemophilus ducreyi and purified cytolethal distending toxin with human monocyte-derived dendritic cells, macrophages and $\mathrm{CD} 4^{+} \mathrm{T}$ cells. Microbes Infect. 6, 1171-1181. doi: 10.1016/j.micinf.2004.07.003

Xynogala, I., Volgina, A., DiRienzo, J., and Korostoff, J. (2009). Evaluation of the humoral immune response to the cytolethal distending toxin of Aggregatibacter actinomycetemcomitans $\mathrm{Y} 4$ in subjects with localized aggressive periodontitis. Oral Microbiol. Immunol. 24, 116-123. doi: 10.1111/j.1399-302X.2008.00483.x

Yamada, T., Komoto, J., Saiki, K., Konishi, K., and Takusagawa, F. (2006). Variation of loop sequence alters stability of cytolethal distending toxin (CDT): crystal structure of CDT from Actinobacillus actinomycetemcomitans. Protein Sci. 15, 362-372. doi: 10.1110/ps.051790506

Yamamoto, K., Tominaga, K., Sukedai, M., Okinaga, T., Iwanaga, K., Nishihara, T., et al. (2004). Delivery of cytolethal distending toxin B induces cell cycle arrest and apoptosis in gingival squamous cell carcinoma in vitro. Eur. J. Oral Sci. 112, 445-451. doi: 10.1111/j.1600-0722.2004.00157.x

Yamano, R., Ohara, M., Nishikubo, S., Fujiwara, T., Kawamoto, T., Ueno, Y., et al. (2003). Prevalence of cytolethal distending toxin production in periodontopathogenic bacteria. J. Clin. Microbiol. 41, 1391-1398. doi: 10.1128/ JCM.41.4.1391-1398.2003

Young, K., Davis, L., and Dirita, V. (2007). Campylobacter jejuni: molecular biology and pathogenesis. Nat. Rev. Microbiol. 5, 665-679. doi: 10.1038/ nrmicro1718

Young, R. S., Fortney, K. R., Gelfanova, V., Phillips, C. L., Katz, B. P., Hood, A. F., et al. (2001). Expression of cytolethal distending toxin and hemolysin is not required for pustule formation by Haemophilus ducreyi in human volunteers. Infect. Immun. 69, 1938-1942. doi: 10.1128/IAI.69.3.1938-1942.2001

Young, V. B., Chien, C. C., Knox, K. A., Taylor, N. S., Schauer, D. B., and Fox, J. G. (2000a). Cytolethal distending toxin in avian and human isolates of Helicobacter pullorum. J. Infect. Dis. 182, 620-623. doi: 10.1086/315705

Young, V. B., Knox, K. A., and Schauer, D. B. (2000b). Cytolethal distending toxin sequence and activity in the enterohepatic pathogen Helicobacter hepaticus. Infect. Immun. 68, 184-191. doi: 10.1128/IAI.68.1.184-191.2000

Young, V. B., Knox, K., Pratt, J. S., Cortz, J. S., Mansfield, L. S., Rogers, A. B., et al. (2004). In vitro and in vivo characterization of Helicobacter hepaticus cytolethal distending toxin mutants. Infect. Immun. 75, 2524-2527. doi: 10.1128/iai.72.5. 2521-2527.2004

Young, V., and Mansfield, L. (2005). "Campylobacter infection - clinical context," in Campylobacter: New Perspectives in Molecular and Cellular Biology, ed J. Ketly (Oxford: Taylor and Francis), 1-12.

Yuan, T., and Cantley, L. (2008). PI3K pathway alterations in cancer: variations on a theme. Oncogene 27, 5497-5510. doi: 10.1038/onc.2008.245

Yue, M., Yang, F., Yang, J., Bei, W., Cai, X., Chen, L., et al. (2009). Complete genome sequence of Haemophilus parasuis SH0165. J. Bacteriol. 191, 1359-1360. doi: $10.1128 / J B .01682-08$

Zhou, M., Zhang, Q., Zhao, J., and Jin, M. (2012). Haemophilus parasuis endcodes two functional cytolethal distending toxins: $\mathrm{CdtC}$ contains an atypical cholesterol recognition/interaction region. PLoS ONE 7:e32580. doi: 10.1371/ journal.pone. 0032580

Conflict of Interest Statement: The authors declare that the research was conducted in the absence of any commercial or financial relationships that could be construed as a potential conflict of interest.

Copyright (c) 2016 Scuron, Boesze-Battaglia, Dlakic and Shenker. This is an openaccess article distributed under the terms of the Creative Commons Attribution License (CC BY). The use, distribution or reproduction in other forums is permitted, provided the original author(s) or licensor are credited and that the original publication in this journal is cited, in accordance with accepted academic practice. No use, distribution or reproduction is permitted which does not comply with these terms. 